\title{
Determination of start times and ordering plans for two-period projects with interdependent demand in project-oriented organizations: A case study on molding industry
}

\author{
Reza Lotfi ${ }^{a^{*}}$, Majid Amin Nayeri ${ }^{b}$, S. Mehdi Sajadifar ${ }^{c}$ and Nooshin Mardani $^{\mathrm{d}}$
}

\section{H R O N I C L E} \\ Article history: \\ Received: July 5, 2017 \\ Received in revised format: Au- \\ gust 28, 2017 \\ Accepted: September 7, 2017 \\ Available online: \\ September 7, 2017 \\ Keywords: \\ Project management \\ Inventory management \\ Two-period interdependent \\ newsvendor \\ Genetic algorithm
}

${ }^{a}$ Department of Industrial Engineering, Yazd University, Yazd, Iran

${ }^{b}$ Department of Industrial Engineering, AmirKabir University, Tehran, Iran

${ }^{c}$ Department of Industrial Engineering, University of Science and Culture, Tehran, Iran

${ }^{d}$ Department of Environment, College of Agriculture, Takestan Branch, Islamic Azad University, Takestan, Iran

\section{A B S T R A C T}

\begin{abstract}
The objective of the present study is to determine the start times and ordering plans for twoperiod projects in project-oriented organizations. The following assumptions are made: orders can be placed in either of a project's two consecutive periods; and the same raw materials are used, which are ordered at the start of the periods according to their interdependent demands. The main innovation of the present research is to develop a model that is mainly based on the two-period newsvendor problem, but assumes that demand is interdependent, i.e. it is actually a combination of inventory and project management. After presenting the model, numerical methods are used to approximate the order quantities for each period. Near-optimal solutions of a numerical example, in a case study on molding industry, are obtained using a genetic algorithm. Results show that the proposed model with interdependent demand provides a better solution than independent demand. The model is applicable to large-scale industrial and construction projects where the majority of raw materials have of the same nature.
\end{abstract}

\section{Introduction}

The timely supply of raw materials is vital for successful completion of construction projects. Effective coordination with suppliers of key materials ensures not only timely procurement of resources, but also reduces the related expenses. Integrated inventory planning is one way to achieve such coordination. Another important decision concerning project management is project start times and ordering plans. Issues concerning quality, storage, and shortages of raw materials can lead to uncertainty in project operations. This in turn leads to further complexity in project management and imposes additional expenses due to suboptimal procurement and storage, along with shortages or excesses in supplies of materials. The lifetime of a project can be divided into two phases: 1) The construction phase, during which the project is gradually established; and 2) The exploitation phase, when the project becomes fully operational. Each phase requires a certain set of raw materials that supply managers are required to order at the beginning of the phase. According to Willoughby (1998), the subject of project inventory * Corresponding author. Tel.: +98 9123455849

E-mail address: rezalotfi@stu.yazd.ac.ir (R. Lotfi) 
control is best modeled as a newsvendor problem. Thus, the present study attempts to model the start times and ordering plans of projects based on the two-period newsboy problem with demand interdependence.

\section{Literature review}

The term "newsvendor" for the single-period stochastic inventory control problem was first introduced by Wilson (Geisler, 1963). The single-period stochastic newsvendor (or newsboy) problem is analogous to a simple supply chain consisting of customers (determining demand), a newsvendor (distributer of a product) and a main supplier. In this problem, the main objective is to determine the amount of the product to order to maximize the profits or minimize the expenses for a single period when demand is stochastic.

\subsection{Single-Period Newsvendor Problem}

Burnetas et al. (2007) examined a problem involving a supply chain consisting of multiple vendors, each with its own demand, and suppliers with service costs and discounts. The objective was to determine the prices that the maximize supply chain revenues. Wang and Webster (2009) rewrote the objective function as a risk function with shortage costs and risk factors. They concluded that when supply shortage costs are higher than supply surplus costs, optimal orders with a risk-averse attitude will be larger than orders with a risk-taking attitude. When shortage costs are lower than threshold values, the opposite will be true. Chen and Ho (2011) formulated a newsboy problem with fuzzy demand and incremental discounts. They incorporated the Yager ranking method into the fuzzy calculations. Given the nonlinearity and complexity of the model, they used the closed-form approach for optimization. In a study by Sana (2012), the above problem was modeled with price-sensitive demand and random sales based on a general probability distribution. In another study, Chen and Ho (2013) analyzed a problem with quantity discounts and proposed a solution based on fuzzy number optimization theory. They also used the Yager ranking method to derive the total costs with different purchase prices as a unique and convex nonlinear function. Okyay et al. (2014) formulated a problem with random supply in which orders can be fulfilled at times other than the beginning of a period. This approach allows supply to be independent of demand when required.

In studies by Kamburowski $(2014,2015)$, a newsboy problem was modeled under worst-case and bestcase scenarios with demand skew. The author proposed a tool for determining best-case and worst-case order quantities when only the first moments of the demand are known. Pal et al. (2015) formulated a newsvendor problem in which customers can reject low-quality products and holding costs depend on order and inventory quantities. Alwan et al. (2016) formulated a newsvendor problem with correlated demand. They compared the performance of a traditional approach for the implementation of the problem with a dynamic forecast-based approach. The authors showed that a minimum mean squared error (MSE) forecast model had better cost savings performance than the traditional approach. The performance of this MSE-optimal approach and the traditional approach was also compared with the performance of widely used alternative forecasting methods such as the moving average and exponential smoothing methods. This article reported that when using alternative forecasting methods, sometimes the traditional approach to the newsvendor problem yields better results, and it is better to disregard correlations and forecasting.

\subsection{Multi-Period Newsvendor Problem}

Perakis and Sood (2004) incorporated the cooperative Nash equilibrium into a multiple-product newsvendor problem to model the sellers' competition. They used game theory and variable inequalities to prove the existence of an equilibrium point for sales. In this problem, the product was assumed 
to be perishable. The use of this approach was recommended for airlines, the service sector, and industrial retailers. Matsuyama (2006) formulated a multiple-product newsvendor problem with unsatisfied demand and unsold quantity in each period. They stated that the order quantity for the next period should be lower when there is surplus inventory and should be higher when demand remains unsatisfied. This model was based on the ratio of the quantity held to the quantity sold and the ratio of the quantity to be sold at the start of the next period to the unsatisfied demand of the current period. Behret and Kahraman (2010) analyzed a multi-period newsvendor problem with fuzzy demand, fuzzy inventory and shortage costs. The objective was to determine the best order periods and the best order quantities to minimize the fuzzy expected total costs. Ding and Gao (2014) considered a $(\sigma, S)$ policy for a multi-product problem with uncertain demand estimated by experts. They optimized orders based on uncertainty theory, and considered variant setup costs depending on the joint or individual status of orders.

\subsection{Multi-Product Newsvendor Problem}

Zhang (2010) formulated a multi-product newsvendor problem with supplier discounts and budget constraints and then optimized the problem using the Lagrangian relaxation algorithm and mixed integer nonlinear programming. Zhang and $\mathrm{Du}$ (2010) examined a multi-product newsvendor problem in which the operation can be outsourced to the supplier with two strategies, zero and non-zero wait times. They then used a binary heuristic algorithm in linear time to optimize the problem. In another study, Zhang and Hua (2010) examined a multi-product newsvendor problem with three strategies: fixed price contracts; multi-option contracts; and portfolio contracts (combination of fixed price and option contracts), all had budget constraints, and the problem was optimized using a new solution of linear complexity based on an assumption of continuous demand. Huang et al. (2011) formulated a competitive multipleproduct newsvendor problem with partial product substitution and a relationship between the demand for two products. They found that competition always leads to higher inventory levels. They also used a recursive algorithm to determine the expected profit for each product based on effective demand estimates.

Hanasusanto et al. (2015) developed a risk-averse multi-dimensional newsvendor model for multiple products with strongly correlated demand. This problem was tailored for demand with strong dependence on mostly unknown future fashion trends whose distribution (called multimodal distribution) is in the form of spatially separated clusters of probability mass. This work was based on the assumption that distributional ambiguity will be addressed by minimization of the worst-case risks of order portfolios for all distributions compatible with the assumed modality. The NP-hard complexity of this problem was proven. An efficient, accurate, and conservative numerical solution was developed based on quadratic decision rules. It was also shown that a solution that disregards ambiguity or multimodality may be unstable and fail to exhibit adequate quality and robustness under stress tests.

Orders for different periods show some inter-period dependency, which has been addressed in recent studies such as Hanasusanto et al. (2015), Alwan et al. (2016) and Okyay et al. (2014). Table 1 summarizes the literature dedicated to the inventory control and newsvendor problem. The approach most suitable for project start times and the order planning is the multi-period newsvendor problem formulated by Matsuyama (2006), in which interdependency of demands for different periods is disregarded. Thus, the present study focuses on incorporation of interdependency into the two-period newsvendor problem approach. The objective is to determine start times and ordering plans for two-period projects with interdependent demands in project-oriented organizations. The resulting formulations are applicable to large-scale projects where a majority of the raw materials are of the same nature. 
Table 1

Classification of the literature.

Reference

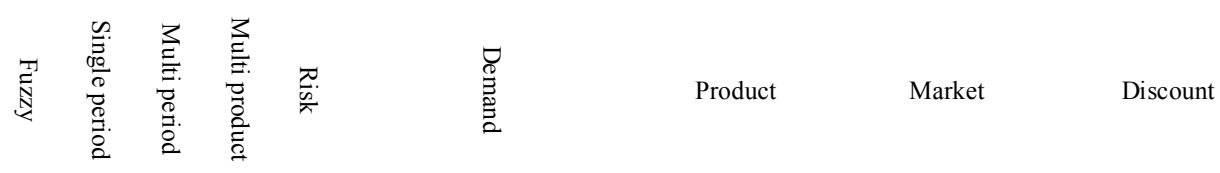

\begin{tabular}{|c|c|c|c|c|c|c|c|c|c|}
\hline Perakis and Sood (2004) & & & 1 & & & Independent & Perishable & Competitive & \\
\hline Matsuyama (2006) & & & 1 & & & Independent & & & \\
\hline Burnetas et al. (2007) & & 1 & & & & Independent & & & Incremental \\
\hline Wang and Webster (2009) & & 1 & & & 1 & Independent & & & \\
\hline $\begin{array}{l}\text { Behret and Kahraman } \\
(2010)\end{array}$ & 1 & & 1 & & & Independent & & & \\
\hline Zhang (2010) & & & & 1 & & Independent & & & All-unit \\
\hline Zhang and Du (2010) & & & & 1 & & Independent & & & \\
\hline Zhang and Hua (2010) & & & & 1 & & Independent & & & \\
\hline Chen and Ho (2011) & 1 & 1 & & & & Independent & & & \\
\hline Huang et al. (2011) & & & & 1 & & Independent & & & \\
\hline Sana (2012) & & 1 & & & & Independent & & & \\
\hline Chen and Ho (2013) & 1 & 1 & & & & Independent & & & \\
\hline Ding and Gao (2014) & & & & 1 & & Independent & & & \\
\hline Kamburowski (2014) & & 1 & & & & Independent & & & \\
\hline Okyay et al. (2014) & & 1 & & & & Independent & & & \\
\hline Kamburowski (2015) & & 1 & & & & Independent & & & \\
\hline Pal and Sana (2015) & & 1 & & & & Independent & & & \\
\hline Hanasusanto et al. (2015) & & & 1 & 1 & 1 & Interdependent & & & \\
\hline Alwan et al. (2016) & & 1 & & & & Interdependent & & & \\
\hline Summary & 3 & 8 & 4 & 6 & 1 & $\begin{array}{l}\text { Independent } 15 \\
\text { Interdependent } 2\end{array}$ & 1 Perishable & 1 Competitive & 1 All-Unit \\
\hline Present study & & & 1 & & & Interdependent D & cheduling + Gen & Algorithm & \\
\hline
\end{tabular}

The rest of this article is organized as follows: Section 3 describes the mathematical formulation of ordering based on an interdependent multi-period newsvendor problem. In section 4, a genetic algorithm is used to solve a numerical example of the problem. In the last section we present conclusions and suggestions for future research. Fig. 1 shows the step-by-step process of implementation of the conceptual model.

Defining the parameters and multivariate distribution function in interdependent demand in multiperiod newsvendor.

Run Genetic algorithm and determine start times scheduling project and Computing the optimal initial inventory between periods (Section 4)

Fig. 1. Process of implementation of the conceptual model

\section{Problem Statement}

In project-oriented organizations, where multiple projects are often ready to start at a given time, effective start times and ordering plans can ensure proper availability of raw materials, which leads to 
minimum costs of shortages and storage and maximum profit. Failure in these tasks may cause avoidable delays in projects and impose unexpected costs and penalties on organizations.

A review of the literature indicates that the formulations of Matsuyama (2006) are the best choice for application to this problem, since they can be generalized for the order policies of interest. In the present study, a multiple-product newsvendor problem is modeled, considering unsatisfied demand, unsold quantities, and interdependency of demand for different periods. When there are unsold goods, the demand for the next period will be lower; when a portion of the demand remains unsatisfied, the demand for the next period will be higher. The model is applicable to large-scale industrial and construction projects where the majority of raw materials are of the same nature.

This problem is modeled based on the following assumptions:

- Each project has one domain and two planning periods.

- There is only a single product (projects require only one type of raw material).

- In each project, the demand for a period depends on the demand for the other period.

- Demands for independent periods are independent random variables.

- Surplus supplies of a period will be used in the next period.

- Out-of-stock supplies of a period will be procured in the next period or will be lost.

- The only objective is to maximize the mean profit from the planned periods.

- The distribution of the demand of each project in each period has a normal distribution.

- The joint distribution of the demands of each project in two periods has a bivariate normal distribution.

For every known plan, the mean value of the profit function is evaluated according to the interdependence of project demand, and the order quantities are optimized at the beginning of the periods accordingly. Since the resulting problem is NP-hard (Geiger, 2017; Yuan et al., 2007), the plan will be obtained by a genetic algorithm.

\subsection{Model Parameters}

\section{Sets of Indices:}

$I$ : Set of projects,

$J$ : Set of planning periods ie $J=\{1,2\}$,

$S$ : The set of states.

\section{Parameters:}

$q_{j}:$ Sell price of the product in the $j^{\text {th }}$ period,

$p_{j} \quad:$ Buy price of the product in the $j^{\text {th }}$ period,

$s_{j} \quad$ : Product holding cost in the $j^{\text {th }}$ period,

$C_{j} \quad:$ Setup cost in the $j^{\text {th }}$ period,

$\pi$ : Shortage penalty (per unit) in the $j^{\text {th }}$ period,

$d_{i} \quad:$ Duration of the $i^{\mathrm{h}}$ projects,

$m$ : Number of periods,

$x_{i j} \quad:$ Demand of the $i^{\text {th }}$ project in the $j^{\text {th }}$ period,

$f\left(x_{i j}, x_{i(j+1)}\right) \quad:$ Joint density function of the $i^{\text {th }}$ project for demands in the $j^{\text {th }}$ and $j+l^{\text {th }}$ periods,

$\mu_{i j}$ : Average of demand of the $i^{\text {th }}$ project in the $j^{\text {th }}$ period,

$\sigma_{i j}^{2}$ : Variance of demand of the $i^{\text {th }}$ project in the $j^{\text {th }}$ period, 
$\rho$ : Correlation of demand of the $i^{\text {th }}$ project in the $j^{\text {th }}$ period and $j+l^{\text {th }}$ periods,

$x_{j} \quad:$ Total demands in the $j^{\text {th }}$ period,

$f\left(x_{j}, x_{j+1}\right) \quad:$ Joint density function of demands in the $j^{\text {th }}$ period and $j+l^{\text {th }}$ period,

$\mu_{j}$ : Average of demand of in the $j^{\text {th }}$ period,

$\sigma_{j}^{2}$ : Variance of demand of in the $j^{\text {th }}$ period,

$\alpha$ : Percentage of the excess inventory to be transferred to the next period,

$\beta$ : Percentage of the inventory shortage to be transferred to the next period,

$\delta$ : Percentage of the sell price in the $j^{\text {th }}$ period to be transferred to the next period,

$L$ : The minimum demand in the $j^{\text {th }}$ period,

$N$ : The maximum demand in the $j^{\text {th }}$ period.

\section{Genetic Algorithm Parameters:}

$n$ : The population number in Genetic Algorithm,

$a$ : The selection operator fraction in Genetic Algorithm,

$b$ : The crossover operator fraction in Genetic Algorithm,

$c$ : The mutation operator fraction in Genetic Algorithm,

$r:$ The random Number in Genetic Algorithm,

\section{Decision variables:}

\section{Inventory:}

$l_{j}:$ The inventory level in the $j^{\text {th }}$ period.

$h_{j s}:$ The profit function in the $j^{\text {th }}$ period in state $s$,

$h_{j}$ : The profit function in the $j^{\text {th }}$ period,

$H$ : The expected value of (mean) total profit in the second period,

$k_{j}, k_{j}^{\prime}, A, B:$ Auxiliary variables in differentiation of $h_{j s}$,

\section{Project scheduling:}

$S_{i}^{\prime} \quad:$ The start time of the $i^{\text {th }}$ project, If the start time of project in first period then $S_{i}^{\prime}=1$, otherwise if the start time of project in second period then $S_{i}^{\prime}=2$.

\subsection{The mathematical model of the inventory problem}

The demand of the project $i$ for the raw material in the period $j$ is a random variable $\left(x_{i j}\right)$ with a joint normal distribution and depends on the start time, as shown in Eq. (1):

$$
x_{i j}, x_{i(j+1)} \sim f\left(x_{i j}, x_{i(j+1)}\right)=N\left(\mu_{i j}, \mu_{i(j+1)}, \sigma_{i j}^{2}, \sigma_{i(j+1)}^{2}, \rho\right) \forall j=1
$$

where $x_{i j}$ can take values if $S_{i}^{\prime} \geq 0$ that is start time of each project. Since the demand for the raw materials required for the projects is assumed to be independent, the total demand in the $j^{\text {th }}$ period is equal to the sum of the demand for raw materials in each project, which is a normal random variable (Eq. (2)): 


$$
\begin{aligned}
& x_{j}=\sum_{i=1}^{I} x_{i j} \quad \forall j \\
& x_{j}, x_{j+1} \sim f\left(x_{j}, x_{j+1}\right)=N\left(\sum_{i=1}^{I} \mu_{i j}, \sum_{i=1}^{I} \mu_{i j+1}, \sum_{i=1}^{I} \sigma_{i j}^{2}, \sum_{i=1}^{I} \sigma_{i j+1}^{2}, \rho\right)=N\left(\mu_{j}, \mu_{j+1}, \sigma_{j}^{2}, \sigma_{j+1}^{2}, \rho\right) \quad \forall j=1
\end{aligned}
$$

In Table 2, $x_{i j}$ denotes the demand of project $i$ for raw material in period $j$. Note that random variables $x_{i j}$ for project $i$ are interdependent between projects and have a joint distribution of $f\left(x_{i j}, x_{i(j+1)}\right) \forall j=1$

Table 2

Model notation

\begin{tabular}{ccc}
\hline Project & $\begin{array}{c}\text { Period 1 } \\
(j=1)\end{array}$ & $\begin{array}{c}\text { Period 2 } \\
(j=2)\end{array}$ \\
\hline$P R_{1}$ & $x_{11}$ & $x_{12}$ \\
$P R_{2}$ & $x_{21}$ & $x_{22}$ \\
$P R_{i}$ & $x_{i 1}$ & $x_{i 2}$ \\
$P R_{n}$ & $x_{n 1}$ & $x_{n 2}$ \\
Total demand in the $\mathrm{j}^{\text {th }}$ period & $x_{1}=\sum_{i=1}^{I} x_{i 1}$ & $x_{2}=\sum_{i=1}^{I} x_{i 2}$ \\
Joint density function & $\left(x_{1}, x_{2}\right) \sim N\left(\mu_{1}, \mu_{2}, \sigma_{1}^{2}, \sigma_{2}^{2}, \rho\right)$. \\
\hline
\end{tabular}

As previously mentioned, in each project, the demand for raw material in period 1 depends on the demand in period 2. So it can be argued that the total demand for raw material in period 1 depends on the total demand for raw material in period 2. This dependence is expressed as a bivariate normal random variable (Eq. (3)) (Tran et al., 2016):

$\left(x_{1}, x_{2}\right) \sim N\left(\mu_{1}, \mu_{2}, \sigma_{1}^{2}, \sigma_{2}^{2}, \rho\right)$.

It is assumed that total demand in the $j^{\text {th }}$ period varies between $L$ and $N$ and under different conditions, the model can take the following states ( $\left.L \leq x_{1} \leq N, L \leq x_{2} \leq N\right)$ :

Initial inventory level $l_{j}$ is between $L$ and $N$ and is higher than demand $x_{j}\left(L \leq x_{j} \leq l_{j} \leq N\right)$.

In this state, the sale quantity for demand $x_{j}$ and sell price $q_{j}$ will be $\left(q_{j} x_{j}\right)$; the unsold quantity will be $\left(l_{j}-x_{j}\right)$. A percentage of the unsold quantity $\alpha\left(l_{j}-x_{j}\right)$ will be stored and transferred to the next period, reducing the order quantity. If this period is the last, then the transfer procedure ends. Otherwise, the order of the next period will be planned with price $P_{j+1}$ and setup $\operatorname{cost} C_{j+1}$. The holding cost will be the product of $s_{j}$ and a percentage of the unsold quantity, i.e., $\mathrm{s}_{j} \alpha\left(l_{j}-x_{j}\right)$. The order quantity of the next period will be equal to the inventory level of the next period minus a percentage of the surplus supply of the previous period, i.e., $l_{j+1}-\alpha\left(l_{j}-x_{j}\right)$.

Initial inventory level $l_{j}$ is lower than demand $x_{j}\left(L \leq l_{j} \leq x_{j} \leq N\right)$.

In this state, the sale quantity for inventory level $l_{j}$ and sell price $q_{j}$ will be $\left(q_{j} l_{j}\right)$; the shortage penalty will be the product of the shortage penalty (per unit) and the quantity of the shortage, i.e., $\pi\left(x_{j}-l_{j}\right)$. In this state, the order quantity of the next period will be equal to the inventory level of the 
next period plus a percentage of the supply shortage of the previous period, i.e., $l_{j+1}+\beta\left(x_{j}-l_{j}\right)$, and will be planned with price $P_{j+1}$ and setup cost $C_{j+1}$. Also, the transferred percentage of supply shortage $\beta\left(x_{j}-l_{j}\right)$ will be sold at a mixed price that is a factor of the sell price in both periods, i.e., $\delta q_{1}+(1-\delta) q_{2}$. In this problem, the profit function of each period $\left(h_{j}\right)$ is a function of the following variables:

$$
h_{j}\left(\alpha, \beta, \delta, \pi, l_{j}, x_{j}\right) \forall j .
$$

In the first period $(j=1)$, the profit function is calculated as follows. This means that when the demand is lower than the inventory level, the revenue equals the sale income from meeting the entire demand of the period minus the initial inventory cost and setup cost (Matsuyama, 2006):

$$
x_{1} \leq l_{1} \Rightarrow h_{1}\left(\alpha, \beta, \delta, \pi, l_{1}, x_{1}\right)=q_{1} x_{1}-p_{1} l_{1}-c_{1} .
$$

However, when the demand is higher than the inventory level, the revenue equals the sale income from the entire initial inventory minus the initial inventory cost, the setup cost, and the cost of the supply shortage (Matsuyama, 2006):

$$
x_{1}>l_{1} \Rightarrow h_{1}\left(\alpha, \beta, \delta, \pi, l_{1}, x_{1}\right)=q_{1} l_{1}-p_{1} l_{1}-\pi\left(x_{1}-l_{1}\right)-c_{1}=\left(q_{1}-p_{1}-\pi\right) l_{1}-\pi x_{1}-c_{1} .
$$

For the second period ( $j=2)$, the profit function is divided into four parts, expressed as follows:

When the demand in period 1 and period 2 is lower than the inventory levels (Eq. (4)), the total revenue equals the revenue of period 1 minus the holding cost for surplus inventory, plus the revenue of period 2 (which equals the sale income from meeting the entire demand of the period minus the inventory cost and the setup cost) (Matsuyama, 2006):

$$
\begin{aligned}
& x_{1} \leq l_{1}, x_{2} \leq l_{2} \Rightarrow h_{21}=h_{2}\left(\alpha, \beta, \delta, \pi, l_{1}, l_{2}, x_{1}, x_{2}\right)=q_{1} x_{1}-p_{1} l_{1}-c_{1} \\
& -s_{1} \alpha\left(l_{1}-x_{1}\right)+q_{2} x_{2}-p_{2}\left(l_{2}-\alpha\left(l_{1}-x_{1}\right)\right)-c_{2} \\
& =h_{1}\left(\alpha, \beta, \delta, \pi, l_{1}, x_{1}\right)-s_{1} \alpha\left(l_{1}-x_{1}\right)+q_{2} x_{2}-p_{2}\left(l_{2}-\alpha\left(l_{1}-x_{1}\right)\right)-c_{2},
\end{aligned}
$$

when the demand in period 1 is lower than the inventory level, but the demand in period 2 is higher than the inventory level (Eq. (5)), total revenue equals the revenue of period 1 minus the holding cost for the surplus inventory, plus the revenue of period 2 (which equals the sale income from the entire initial inventory minus the inventory cost, the setup cost, and the cost of the supply shortage) (Matsuyama, 2006):

$$
\begin{aligned}
& x_{1} \leq l_{1}, x_{2}>l_{2} \Rightarrow \\
& h_{22}=h_{2}\left(\alpha, \beta, \delta, \pi, l_{1}, l_{2}, x_{1}, x_{2}\right)=q_{1} x_{1}-p_{1} l_{1}-c_{1}-s_{1} \alpha\left(l_{1}-x_{1}\right) \\
& +q_{2} l_{2}-p_{2}\left(l_{2}-\alpha\left(l_{1}-x_{1}\right)\right)-\pi\left(x_{2}-l_{2}\right)-c_{2}=h_{1}\left(\alpha, \beta, \delta, \pi, l_{1}, x_{1}\right) \\
& -S_{1} \alpha\left(l_{1}-x_{1}\right)+q_{2} l_{2}-p_{2}\left(l_{2}-\alpha\left(l_{1}-x_{1}\right)\right)-\pi\left(x_{2}-l_{2}\right)-c_{2} .
\end{aligned}
$$

When the demand in period 1 is higher than the inventory level, but the demand in period 2 is lower than the inventory level (Eq. (6)), the total revenue equals the revenue of period 1 plus the income from selling the supply shortage of period 1 at a mixed price in period 2 , plus the revenue of period 2 (which equals the sale income from meeting the entire demand of the period minus the inventory cost and the setup cost) (Matsuyama, 2006):

$$
x_{1}>l_{1}, x_{2} \leq l_{2} \Rightarrow
$$




$$
\begin{aligned}
& h_{23}=h_{2}\left(\alpha, \beta, \delta, \pi, l_{1}, l_{2}, x_{1}, x_{2}\right)=q_{1} l_{1}-p_{1} l_{1}-\pi\left(x_{1}-l_{1}\right)-c_{1} \\
& +\left(\delta q_{1}+(1-\delta) q_{2}\right) \beta\left(x_{1}-l_{1}\right)+q_{2} x_{2}-p_{2}\left(l_{2}+\beta\left(x_{1}-l_{1}\right)\right)-c_{2} \\
& =h_{1}\left(\alpha, \beta, \delta, \pi, l_{1}, x_{1}\right)+\left(\delta q_{1}+(1-\delta) q_{2}\right) \beta\left(x_{1}-l_{1}\right)+q_{2} x_{2}-p_{2}\left(l_{2}+\beta\left(x_{1}-l_{1}\right)\right)-c_{2},
\end{aligned}
$$

When the demand in period 1 is higher than the inventory level, and the demand in period 2 is also higher than the inventory level (Eq. (7)), the total revenue equals the revenue of period 1 plus the income from selling the supply shortage of period 1 at a mixed price in period 2, plus the revenue of period 2 (which equals the sale income from the entire inventory minus the inventory cost, the setup cost, and the cost of the supply shortage) (Matsuyama, 2006):

$$
\begin{aligned}
& x_{1}>l_{1}, x_{2}>l_{2} \Rightarrow \\
& h_{24}=h_{2}\left(\alpha, \beta, \delta, \pi, l_{1}, l_{2}, x_{1}, x_{2}\right)=q_{1} l_{1}-p_{1} l_{1}-\pi\left(x_{1}-l_{1}\right)-c_{1} \\
& +\left(\delta q_{1}+(1-\delta) q_{2}\right) \beta\left(x_{1}-l_{1}\right)+q_{2} l_{2}-p_{2}\left(l_{2}+\beta\left(x_{1}-l_{1}\right)\right)-\pi\left(x_{2}-l_{2}\right)-c_{2} \\
& =h_{1}\left(\alpha, \beta, \delta, \pi, l_{1}, x_{1}\right)+\left(\delta q_{1}+(1-\delta) q_{2}\right) \beta\left(x_{1}-l_{1}\right) \\
& +q_{2} l_{2}-p_{2}\left(l_{2}+\beta\left(x_{1}-l_{1}\right)\right)-\pi\left(x_{2}-l_{2}\right)-c_{2} .
\end{aligned}
$$

Given the dependence of the demand of period 2 on the demand of period 1, the mean total profit can be obtained by calculating the mathematical expectation of profit in second period:

$$
\begin{aligned}
& H\left(l_{1}, l_{2}, x_{1}, x_{2}\right)=\int_{q\left(l_{1}\right)} \int_{p\left(l_{2}\right)} h_{2}\left(l_{1}, l_{2}, x_{1}, x_{2}\right) f\left(x_{1}, x_{2}\right) d x_{2} d x_{1} \\
& =\int_{-\infty}^{l_{2}} \int_{-\infty}^{l_{1}} h_{2}\left(l_{1}, l_{2}, x_{1}, x_{2}\right) f\left(x_{1}, x_{2}\right) d x_{1} d x_{2}+\int_{l_{2}-\infty}^{\infty} \int_{l_{1}}^{l_{1}} h_{2}\left(l_{1}, l_{2}, x_{1}, x_{2}\right) f\left(x_{1}, x_{2}\right) d x_{1} d x_{2} \\
& +\int_{-\infty}^{l_{2}} \int_{l_{1}}^{\infty} h_{2}\left(l_{1}, l_{2}, x_{1}, x_{2}\right) f\left(x_{1}, x_{2}\right) d x_{1} d x_{2}+\int_{l_{2}}^{\infty} \int_{1}^{\infty} h_{2}\left(l_{1}, l_{2}, x_{1}, x_{2}\right) f\left(x_{1}, x_{2}\right) d x_{1} d x_{2} .
\end{aligned}
$$

To obtain optimal values of $l_{1}^{*}, l_{2}^{*}$, the expected value of the profit function must be differentiated with respect to $l_{1}^{*}, l_{2}^{*}$ and then equated to zero (Eq. (8) and Eq. (9)):

$$
\begin{aligned}
& \frac{\partial}{\partial l_{1}} H\left(l_{1}, l_{2}, x_{1}, x_{2}\right)=0, \\
& \frac{\partial}{\partial l_{2}} H\left(l_{1}, l_{2}, x_{1}, x_{2}\right)=0 .
\end{aligned}
$$

The differentiation process is explained in Appendix 1 and gives the joint cumulative distribution of $l_{1}^{*}$ as Eq. (10):

$$
F\left(l_{1}^{*}\right)=\int_{-\infty}^{\infty} \int_{-\infty}^{l_{1}^{*}} f\left(x_{1}, x_{2}\right) d x_{1} d x_{2}=\frac{q_{1}-p_{1}+\pi-\beta\left(\delta q_{1}+(1-\delta) q_{2}\right)+p_{2} \beta}{q_{1}+\pi-\beta\left(\delta q_{1}+(1-\delta) q_{2}\right)+p_{2} \beta+\alpha\left(s_{1}-p_{2}\right)} .
$$

Similarly, subjecting Eq. (9) to the process explained in Appendix 1 gives Eq. (11):

$$
F\left(l_{2}^{*}\right)=\int_{-\infty}^{\infty} \int_{-\infty}^{l_{2}^{*}} f\left(x_{1}, x_{2}\right) d x_{2} d x_{1}=\frac{q_{2}-p_{2}+\pi}{q_{2}+\pi} .
$$


A Hessian matrix (second derivative test) is used to determine whether $l_{1}^{*}$ and $l_{2}^{*}$ are maximum, minimum or inflection points (Abramowitz, 1964). The results obtained from the Hessian matrix are given in Appendix 2. The determinant of $H\left(l_{1}, l_{2}, x_{1}, x_{2}\right)$ for $l_{1}^{*}, l_{2}^{*}$ is positive and $\left(k_{2}-k_{4}\right) \frac{\partial}{\partial l_{1}} F\left(l_{1}\right)_{l_{2}=l_{2}^{*}}^{l_{1}=l_{1}^{*}}<0$.

Therefore, $l_{1}^{*}, l_{2}^{*}$ are the relative maximums for $H\left(l_{1}^{*}, l_{2}^{*}, x_{1}, x_{2}\right)$ (Dye \& Ouyang, 2005). Given the dependence of the demand in the two consecutive periods and its relatively normal behavior, a bivariate normal distribution is the best choice for distribution of the demand. Bivariate normal distribution:

$$
f\left(x_{1}, x_{2}\right)=\frac{1}{2 \pi \sigma_{1} \sigma_{2} \sqrt{1-\rho^{2}}} * e^{-\frac{1}{2\left(1-\rho^{2}\right)}\left(\left(\frac{x_{1}-\mu_{1}}{\sigma_{1}}\right)^{2}-2 \rho\left(\frac{x_{1}-\mu_{1}}{\sigma_{1}}\right)\left(\frac{x_{2}-\mu_{2}}{\sigma_{2}}\right)+\left(\frac{x_{2}-\mu_{2}}{\sigma_{2}}\right)^{2}\right)} .
$$

Given the presence of the term ( $L \leq x_{1} \leq N, L \leq x_{2} \leq N$ ) in the above distribution, the demand distribution function needs to be truncated in order to give the final demand distribution function. The truncated demand distribution function can be defined as (Singh et al., 2016):

$$
\begin{aligned}
f\left(x_{1}, x_{2} \mid L \leq x_{1} \leq N, L \leq x_{2} \leq N\right) & =\frac{f\left(x_{1}, x_{2}\right)}{F(N, N)-F(L, N)-F(N, L)+F(L, L)}, \\
& =\frac{N\left(\mu_{1}, \mu_{2}, \sigma_{1}^{2}, \sigma_{2}^{2}, \rho\right)}{F(N, N)-F(L, N)-F(N, L)+F(L, L)} .
\end{aligned}
$$

The truncated demand distribution function is defined as follows where Eq. (10) is rewritten as

$$
\begin{aligned}
& F(a, b)=\int_{-\infty}^{a} \int_{-\infty}^{b} f\left(x_{1}, x_{2}\right) d x_{1} d x_{2}: \\
& F\left(l_{1}^{*}, N\right)=\int_{L}^{N l_{1}^{*}} f\left(x_{L}, x_{2}\right) d x_{1} d x_{2}=\int_{L}^{N} \int_{L}^{l_{1}^{*}} \frac{N\left(\mu_{1}, \mu_{2}, \sigma_{1}^{2}, \sigma_{2}^{2}, \rho\right)}{F(N, N)-F(L, N)-F(N, L)+F(L, L)} d x_{1} d x_{2} \\
& =\frac{\int_{L}^{N} \int_{L}^{l_{1}^{*}} N\left(\mu_{1}, \mu_{2}, \sigma_{1}^{2}, \sigma_{2}^{2}, \rho\right) d x_{1} d x_{2}}{[F(N, N)-F(L, N)-F(N, L)+F(L, L)]}=\frac{\left[F\left(l_{1}^{*}, N\right)-F(L, N)-F\left(l_{1}^{*}, L\right)+F(L, L)\right]}{[F(N, N)-F(L, N)-F(N, L)+F(L, L)]} \\
& =\frac{q_{1}-p_{1}+\pi-\beta\left(\delta q_{1}+(1-\delta) q_{2}\right)+p_{2} \beta}{q_{1}+\pi-\beta\left(\delta q_{1}+(1-\delta) q_{2}\right)+p_{2} \beta+\alpha\left(s_{1}-p_{2}\right)}
\end{aligned}
$$

Eq. (11) is rewritten as:

$$
\begin{aligned}
& F\left(N, l_{2}^{*}\right)=\int_{L}^{N l_{L}^{*}} f\left(x_{1}, x_{2}\right) d x_{2} d x_{1}=\int_{L L}^{N l_{2}^{*}} \frac{N\left(\mu_{1}, \mu_{2}, \sigma_{1}^{2}, \sigma_{2}^{2}, \rho\right)}{F(N, N)-F(L, N)-F(N, L)+F(L, L)} d x_{2} d x_{1} \\
& =\frac{\iint_{L L}^{N} \int_{L_{2}} N\left(\mu_{1}, \mu_{2}, \sigma_{1}^{2}, \sigma_{2}^{2}, \rho\right) d x_{2} d x_{1}}{[F(N, N)-F(L, N)-F(N, L)+F(L, L)]}=\frac{\left[F\left(N, l_{2}^{*}\right)-F(N, L)-F\left(L, l_{2}^{*}\right)+F(L, L)\right]}{[F(N, N)-F(L, N)-F(N, L)+F(L, L)]} \\
& =\frac{q_{2}-p_{2}+\pi}{q_{2}+\pi}
\end{aligned}
$$


Because computations of $l_{1}^{*}, l_{2}^{*}$ from $\int_{L}^{N} \int_{L}^{l_{1}^{*}} f\left(x_{1}, x_{2}\right) d x_{1} d x_{2}$ and $\int_{L}^{N} \int_{L}^{l_{2}^{*}} f\left(x_{1}, x_{2}\right) d x_{2} d x_{1}$ are very hard then they can be calculated with the help of the following numerical approach

\subsection{Sensitivity analysis}

For better examination of the problem's seven parameters, a sensitivity analysis is performed by differentiation. The results of this analysis are given below (Eq. s (15-22)):

$$
\begin{aligned}
& \frac{\partial}{\partial q_{1}} H\left(l_{1}, l_{2}, x_{1}, x_{2}\right)>0, \\
& \frac{\partial}{\partial q_{2}} H\left(l_{1}, l_{2}, x_{1}, x_{2}\right)>0 \\
& \frac{\partial}{\partial p_{1}} H\left(l_{1}, l_{2}, x_{1}, x_{2}\right)=-l_{1}<0 \\
& \frac{\partial}{\partial \pi} H\left(l_{1}, l_{2}, x_{1}, x_{2}\right)<0 \\
& \frac{\partial}{\partial \alpha} H\left(l_{1}, l_{2}, x_{1}, x_{2}\right)=\frac{p_{2}-s_{1}}{\left|p_{2}-s_{1}\right|}, \\
& \frac{\partial}{\partial \beta} H\left(l_{1}, l_{2}, x_{1}, x_{2}\right)=\frac{\left(\delta q_{1}+(1-\delta) q_{2}\right)-p_{2}}{\left|\left(\delta q_{1}+(1-\delta) q_{2}\right)-p_{2}\right|}, \\
& \frac{\partial}{\partial \delta} H\left(l_{1}, l_{2}, x_{1}, x_{2}\right)=\frac{q_{1}-q_{2}}{\left|q_{1}-q_{2}\right|}, \\
& \frac{\partial}{\partial p_{2}} H\left(l_{1}, l_{2}, x_{1}, x_{2}\right)=-l_{2}+\alpha\left(l_{1}-\mu_{1}\right)+(\alpha-\beta) \int_{-\infty l_{1}}^{\infty} \int_{1}^{\infty}\left(x_{1}-l_{1}\right) f\left(x_{1}, x_{2}\right) d x_{1} d x_{2} .
\end{aligned}
$$

Eq. (15) and Eq. (16) show that for all $q_{1}, q_{2}$ the value of $H\left(l_{1}, l_{2}, x_{1}, x_{2}\right)$ is ascending and for $\pi, p_{1}$ the value of $H\left(l_{1}, l_{2}, x_{1}, x_{2}\right)$ is descending in Eq. (17) and Eq. (18).

The value of other parameters such as $\alpha, \beta$, and $\delta$ depend on sign of $p_{2}-s_{1},\left(\delta q_{1}+(1-\delta) q_{2}\right)-p_{2}$ and $q_{1}-q_{2}$ in Eqs. (19-21). Moreover, $H\left(l_{1}, l_{2}, x_{1}, x_{2}\right)$ is ascending whenever they are positive, and is descending otherwise in Eqs. (19-21).

However, the parameter $p_{2}$ depends on other parameters and its status is unknown. $\frac{\partial}{\partial p_{2}} H\left(l_{1}, l_{2}, x_{1}, x_{2}\right)$ depends on the above terms, which may be positive or negative.

\section{Solution method for scheduling project}

The objective of the present study is to determine the start times and ordering plans for two-period projects in project-oriented organizations. Given the NP-hard complexity of the project start time and ordering problem, and the nonlinearity of the model described in Section 3, this model is solved with a genetic algorithm, which is one of the most commonly used algorithms for scheduling problems (Holland,1975; Diabat, 2014; Puga et al., 2016). The genetic algorithm developed for the investigated problem is shown in Fig. 2. 


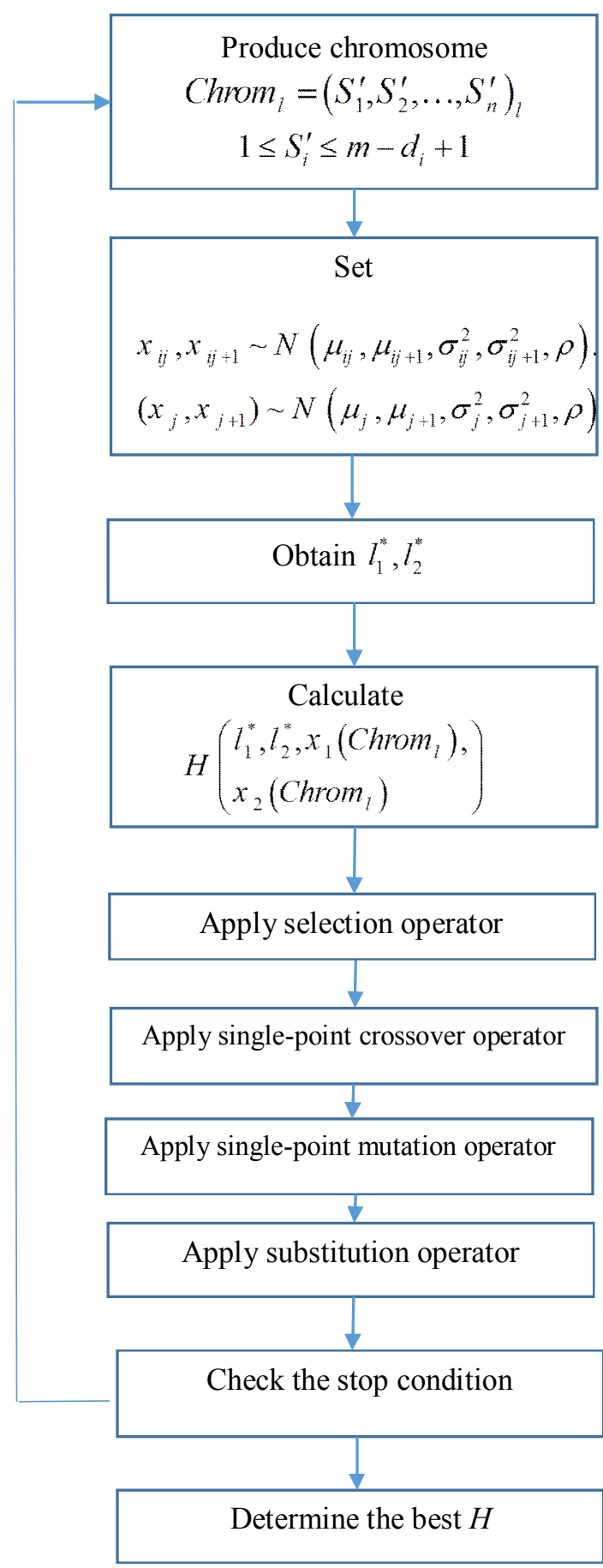

Fig. 2. Genetic algorithm for the problem

According to the final model described in section 3, the objective function is defined as follows,

$\max H\left(l_{j}, l_{j+1}, x_{j}, x_{j+1}\right)=\int_{-\infty}^{l_{2}} \int_{-\infty}^{l_{1}} h_{2}\left(l_{1}, l_{2}, x_{1}, x_{2}\right) f\left(x_{1}, x_{2}\right) d x_{1} d x_{2}+\int_{l_{2}-\infty}^{\infty} \int_{-\infty}^{l_{1}} h_{2}\left(l_{1}, l_{2}, x_{1}, x_{2}\right) f\left(x_{1}, x_{2}\right)$

$+\int_{-\infty}^{l_{2}} \int_{1}^{\infty} h_{2}\left(l_{1}, l_{2}, x_{1}, x_{2}\right) f\left(x_{1}, x_{2}\right) d x_{1} d x_{2}+\int_{l_{2}}^{\infty} \int_{l_{1}}^{\infty} h_{2}\left(l_{1}, l_{2}, x_{1}, x_{2}\right) f\left(x_{1}, x_{2}\right) d x_{1} d x_{2}$

subject to

$x_{i j}\left(S_{1}^{\prime}, S_{2}^{\prime}, \ldots, S_{I}^{\prime}\right), x_{i(j+1)}\left(S_{1}^{\prime}, S_{2}^{\prime}, \ldots, S_{I}^{\prime}\right) \sim N\left(\mu_{i j}, \mu_{i(j+1)}, \sigma_{i j}^{2}, \sigma_{i(j+1)}^{2}, \rho\right) \quad \forall j=1$ 


$$
\begin{array}{ll}
\left(x_{j}, x_{j+1}\right) \sim N\left(\mu_{j}, \mu_{j+1}, \sigma_{j}^{2}, \sigma_{j+1}^{2}, \rho\right) & \forall j= \\
L \leq x_{j} \leq N & \forall j= \\
S_{i}^{\prime}=\{1,2\} \text { and integer } & \forall i \subset
\end{array}
$$

Each chromosome comprises the start times of the projects is Chrom $_{l}=\left(S_{1}^{\prime}, S_{2}^{\prime}, \ldots, S_{I}^{\prime}\right)_{l}$ in Fig. 3:

\begin{tabular}{|c|c|c|c|}
\hline$S_{1}^{\prime}$ & $S_{2}^{\prime}$ & $\cdots$ & $S_{I}^{\prime}$ \\
\hline
\end{tabular}

Fig. 3. Representation of a chromosome

1. First, random numbers are used to produce a population $(n)$ of chromosomes that meet the following condition for $S_{i}^{\prime}$ (start times) and $S_{i}^{\prime}=\{1,2\} \forall i \subset I$.

2. Given the $S_{i}^{\prime}$ values obtained from $S_{i}^{\prime}=\{1,2\} \forall i \subset I, x_{i j}$ takes the value of a defined density function $x_{i j}, x_{i(j+1)} \sim N\left(\mu_{i j}, \mu_{i(j+1)}, \sigma_{i j}^{2}, \sigma_{i(j+1)}^{2}, \rho\right) \forall j=1$. (normal distribution function) (Jun \& Park, 2015):

3. Aggregating the $x_{i j}$ values gives total demand $x_{j}$ as follows:

$$
\left(x_{j}, x_{j+1}\right) \sim N\left(\mu_{j}, \mu_{j+1}, \sigma_{j}^{2}, \sigma_{j+1}^{2}, \rho\right) \forall j=1
$$

Note that the demand should be $L \leq x_{j} \leq N$, otherwise Step 2 must be repeated to produce a new chromosome.

4. Values of $l_{1}^{*}, l_{2}^{*}$ for each chromosome are obtained through Eq. s (14) and (14a).

5. For each chromosome, $l_{1}^{*}, l_{2}^{*}$ values are replaced in the function $H$

$$
\begin{aligned}
& H\left(l_{1}^{*}, l_{2}^{*}, x_{1}\left(\text { Chrom }_{i}\right), x_{2}\left(\text { Chrom }_{i}\right)\right)=\int_{-\infty}^{l_{2}^{*}} \int_{-\infty}^{l_{1}^{*}} h_{2}\left(l_{1}, l_{2}, x_{1}, x_{2}\right) f\left(x_{1}, x_{2}\right) d x_{1} d x_{2} \\
& +\int_{l_{2}^{*}-\infty}^{\infty} \int_{1}^{l_{1}^{*}} h_{2}\left(l_{1}, l_{2}, x_{1}, x_{2}\right) f\left(x_{1}, x_{2}\right) d x_{1} d x_{2}+\int_{-\infty}^{l_{2}^{*}} \int_{l_{1}^{*}}^{\infty} h_{2}\left(l_{1}, l_{2}, x_{1}, x_{2}\right) f\left(x_{1}, x_{2}\right) d x_{1} d x_{2} \\
& +\int_{l_{2}^{*} l_{1}^{*}}^{\infty} h_{2}\left(l_{1}, l_{2}, x_{1}, x_{2}\right) f\left(x_{1}, x_{2}\right) d x_{1} d x_{2} .
\end{aligned}
$$

6. The values of $H$ for $n$ members are obtained and sorted in descending order (Eq. (23)).

7. Selection operator: a fraction ( $a \%)$ of the sorted items remain as part of the future population. Another fraction of the items is selected by a competitive selection operation, to be subjected to crossover and mutation operators and then undergo the next step (Marinakis et al., 2008; Lotfi et al., 2017).

8. Crossover operator: A crossover operator is applied to $b \%$ of the population. This operator produces two new members from members $l$ and $m$ by cutting these members based on a randomly generated number $r$ and swapping the cut sections. The demand of new chromosomes must remain within the defined range; otherwise the objective function will be penalized (Roy \& Mula, 2016; Lotfi \& Amin Nayeri, 2016):

$$
\begin{aligned}
& 1 \leq r<|I|, \\
& \text { Chrom }_{l}=\left(S_{1}^{\prime}, S_{2}^{\prime}, \ldots, S_{n}^{\prime}\right)_{l}, \text { Chrom }_{m}=\left(S_{1}^{\prime}, S_{2}^{\prime}, \ldots, S_{n}^{\prime}\right)_{m}, \\
& \text { newchrom }_{l m}=\left(S_{1}^{\prime}, S_{2}^{\prime}, \ldots S_{r}^{\prime}\right)_{l}\left(S_{r+1}^{\prime}, \ldots, S_{I}^{\prime}\right)_{m}, \\
& \text { newchrom }_{l m}^{\prime}=\left(S_{1}^{\prime}, S_{2}^{\prime}, \ldots S_{r}^{\prime}\right)_{m}\left(S_{r+1}^{\prime}, \ldots, S_{I}^{\prime}\right)_{l} .
\end{aligned}
$$


9. Mutation operator: A mutation operator is applied to $c \%$ of the population. This operator transforms chromosome $i$ based on a randomly generated number $1 \leq r<|I|$. Again, the demand of new chromosomes must remain within the range defined in Step 1; otherwise, the objective function will be penalized (Ghaddar et al., 2016):

newchrom $_{l m}=\left(\left(S_{1}^{\prime}, S_{2}^{\prime}, \ldots S_{r-1}^{\prime}\right)_{l}\right.$, new $\left.S_{r}^{\prime},\left(S_{r+1}^{\prime}, \ldots, S_{I}^{\prime}\right)_{m}\right)$.

10. Substitution: $H$ values of the new population produced in steps 7,8 and 9 are recalculated, and all the values are sorted in descending order of the mean profit function value.

11. Loop and stop conditions: This loop continues until the difference between the best solutions of two consecutive iterations becomes lower than a specific value. Otherwise, Step 7 will be repeated; ultimately, the chromosome with the highest $H$ value will be obtained (Qiongbing \& Lixin, 2016; Sivanandam \& Deepa, 2007).

\section{Numerical example}

A case study is studied in Iran Khodro Advance Die (IKAD) that produces dies with a lot of steel for Iran Khodro automotive company in one year. It has $i=12$ projects that are ready to start. All the projects have two planning periods (six month $(m=2)$ ); their specifications are shown in Table 3. Raw materials bought at price $p_{j}=$ Uniform $(2,3)$ are sold in these projects with price $q_{j}=\operatorname{Uniform}(9,10)$; the holding cost is $s_{j}=\operatorname{Uniform}(1,2)$ and the shortage penalty is $\pi=\operatorname{Uniform}(1,2) . \alpha=100 \%$ of the surplus inventory and $\beta=100 \%$ of the inventory shortage will be transferred to the next period. Outof-stock materials of period 1 will be sold in period 2 at $\delta=60 \%$ of the initial price (the price of period 1). The demand of the periods have $(\rho=-50 \%)$ interdependence; $L=144.33$ and $N=286.67$.

Table 3

Specifications of the numerical example

\begin{tabular}{|c|c|c|c|c|c|}
\hline \multirow[t]{2}{*}{ Project } & \multirow{2}{*}{ Start time $S_{i}^{\prime}$} & \multirow{2}{*}{ Duration $d_{i}$} & \multicolumn{2}{|c|}{ Demand without scheduling } & \multirow[t]{2}{*}{$\rho$} \\
\hline & & & Period 1 & Period 2 & \\
\hline$P R_{1}$ & $S_{1}^{\prime}$ & 1 & $N(10,1)$ & 0 & $-50 \%$ \\
\hline$P R_{2}$ & $S_{2}^{\prime}$ & 2 & $N(20,2)$ & $N(20,2)$ & $-50 \%$ \\
\hline$P R_{3}$ & $S_{3}^{\prime}$ & 1 & $N(40,4)$ & 0 & $-50 \%$ \\
\hline$P R_{4}$ & $S_{4}^{\prime}$ & 1 & $N(30,3)$ & 0 & $-50 \%$ \\
\hline$P R_{5}$ & $S_{5}^{\prime}$ & 1 & $N(35,3.5)$ & 0 & $-50 \%$ \\
\hline$P R_{6}$ & $S_{6}^{\prime}$ & 1 & $N(45,4.5)$ & 0 & $-50 \%$ \\
\hline$P R_{7}$ & $S_{7}^{\prime}$ & 1 & $N(50,5)$ & 0 & $-50 \%$ \\
\hline$P R_{8}$ & $S_{8}^{\prime}$ & 1 & $N(43,4.3)$ & 0 & $-50 \%$ \\
\hline$P R_{9}$ & $S_{9}^{\prime}$ & 1 & $N(90,9)$ & 0 & $-50 \%$ \\
\hline$P R_{10}$ & $S_{10}^{\prime}$ & 1 & $N(20,2)$ & 0 & $-50 \%$ \\
\hline$P R_{11}$ & $S_{11}^{\prime}$ & 1 & $N(10,1)$ & 0 & $-50 \%$ \\
\hline$P R_{12}$ & $S_{12}^{\prime}$ & 2 & $N(10,1)$ & $N(10,1)$ & $-50 \%$ \\
\hline \multicolumn{2}{|c|}{ Sell rice } & $q_{j}$ & \multicolumn{2}{|c|}{ Uniform $(9,10)$} & \\
\hline \multicolumn{2}{|c|}{ Buy rice } & $p_{j}$ & \multicolumn{2}{|c|}{ Uniform(2,3) } & \\
\hline \multicolumn{2}{|c|}{ Holding cost } & $s_{j}$ & \multicolumn{2}{|c|}{ Uniform(1,2) } & \\
\hline \multicolumn{2}{|c|}{ Shortage penalty } & $\pi$ & \multicolumn{2}{|c|}{ Uniform $(1,2)$} & \\
\hline
\end{tabular}


Tuning algorithm parameters with design of experiment (DOE based on Taguchi algorithm is accomplished (Mousavi et al. (2014)): Population size is $n=50 ; a=9 \%$ of the population, which is transferred to the next generation; $b=89 \%$ of the population, which is subjected to the crossover operator; and $c=2 \%$ of the population, which is subjected to the mutation operator. The stop condition is iter $=50$ or when the difference between the consecutive results is less than $\varepsilon=0.01$. The results of the algorithm are presented in Table 4 and Fig. 4 and tuning of parameters of Genetic algorithm is obtained from design of experiment. The process of finding a near-optimal result with genetic algorithm is shown in Fig. 4.

Table 4

Final results of the genetic algorithm

\begin{tabular}{|c|c|c|c|}
\hline Start time $\left(S_{i}^{\prime}\right)$ & $\begin{array}{c}\text { Demand of period } 1 \\
x_{i 1}\end{array}$ & $\begin{array}{c}\text { Demand of period } 2 \\
x_{i 2}\end{array}$ & $\rho$ \\
\hline$S_{1}^{\prime}=1$ & $N(10,1)$ & 0 & $-50 \%$ \\
\hline$S_{2}^{\prime}=1$ & $N(20,2)$ & $N(20,2)$ & $-50 \%$ \\
\hline$S_{3}^{\prime}=2$ & 0 & $N(40,4)$ & $-50 \%$ \\
\hline$S_{4}^{\prime}=2$ & 0 & $N(30,3)$ & $-50 \%$ \\
\hline$S_{5}^{\prime}=2$ & 0 & $N(35,3.5)$ & $-50 \%$ \\
\hline$S_{6}^{\prime}=2$ & 0 & $N(45,4.5)$ & $-50 \%$ \\
\hline$S_{7}^{\prime}=1$ & $N(50,5)$ & 0 & $-50 \%$ \\
\hline$S_{8}^{\prime}=1$ & $N(43,4.3)$ & 0 & $-50 \%$ \\
\hline$S_{9}^{\prime}=1$ & $N(90,9)$ & 0 & $-50 \%$ \\
\hline$S_{10}^{\prime}=1$ & $N(20,2)$ & 0 & $-50 \%$ \\
\hline$S_{11}^{\prime}=2$ & 0 & $N(10,1)$ & $-50 \%$ \\
\hline$S_{12}^{\prime}=1$ & $N(10,1)$ & $N(10,1)$ & $-50 \%$ \\
\hline $\begin{array}{l}\text { Total demand in the } \\
j^{\text {th }} \text { period }\end{array}$ & $N(243,11.59)$ & $N(190,7.96)$ & \\
\hline $\begin{array}{l}\text { Joint density func- } \\
\text { tion }\end{array}$ & \multicolumn{2}{|c|}{$N(243,190,11.59,7.96,-50 \%)$} & $-50 \%$ \\
\hline Best Solution & $l_{1}^{*}=243.00$ & $l_{2}^{*}=198.82$ & \\
\hline Profit & \multicolumn{2}{|c|}{$H^{*}=2992.5$} & \\
\hline
\end{tabular}

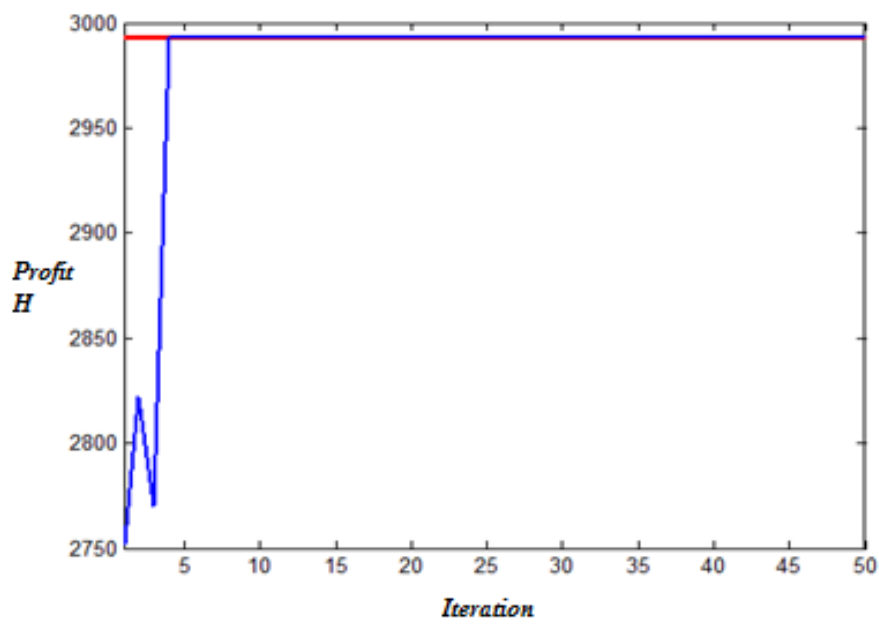

Fig. 4. The final solution of the genetic algorithm 


$$
\begin{aligned}
& \left(k_{2}-k_{4}\right)=-\left(q_{1}+\pi-\beta\left(\delta q_{1}+(1-\delta) q_{2}\right)+p_{2} \beta+\alpha\left(s_{1}-p_{2}\right)\right) \\
& =-(10+1-1 * 10+1 * 3+1) *(1-3))=-2<0 .
\end{aligned}
$$

Based on the assumption expressed in Eq. (24) and Eq. (A-8) and the results shown in Table 4 we reach the optimum point, and the optimal inventory levels of periods 1 and 2 are $l_{1}^{*}=243.00$ and $l_{2}^{*}=198.82$. The start times of the projects are obtained as shown in Table 3 in column one; and the profit of the organizations is $H^{*}=2992.5$. Tables 5-7 and Figs. 4-6 show sensitivity analysis of the ratio $\alpha, \beta, \delta$ that have prooved base on differentiation in Eq. (15), Eq. (17) and Eq. (18). When these parameters such as $\alpha, \beta$ and $\delta$ grow up, as result $H$ grows up.

Table 5

Sensitivity analysis of the ratio $(\alpha)$

\begin{tabular}{cccc}
\hline Percentage of excess inventory $(\alpha)$ & Profit & Inventory & \multicolumn{2}{c}{ Inventory } \\
& $H^{*}$ & $l_{1}^{*}$ & 189.54 \\
$20 \%$ & 2988.2 & 240.98 & 202.79 \\
$40 \%$ & 2988.9 & 229.32 & 192.59 \\
$60 \%$ & 2990.5 & 240.66 & 189.58 \\
$80 \%$ & 2991.3 & 245.5 & 194.82 \\
$100 \%$ & 2992.5 & 243 & \\
\hline
\end{tabular}

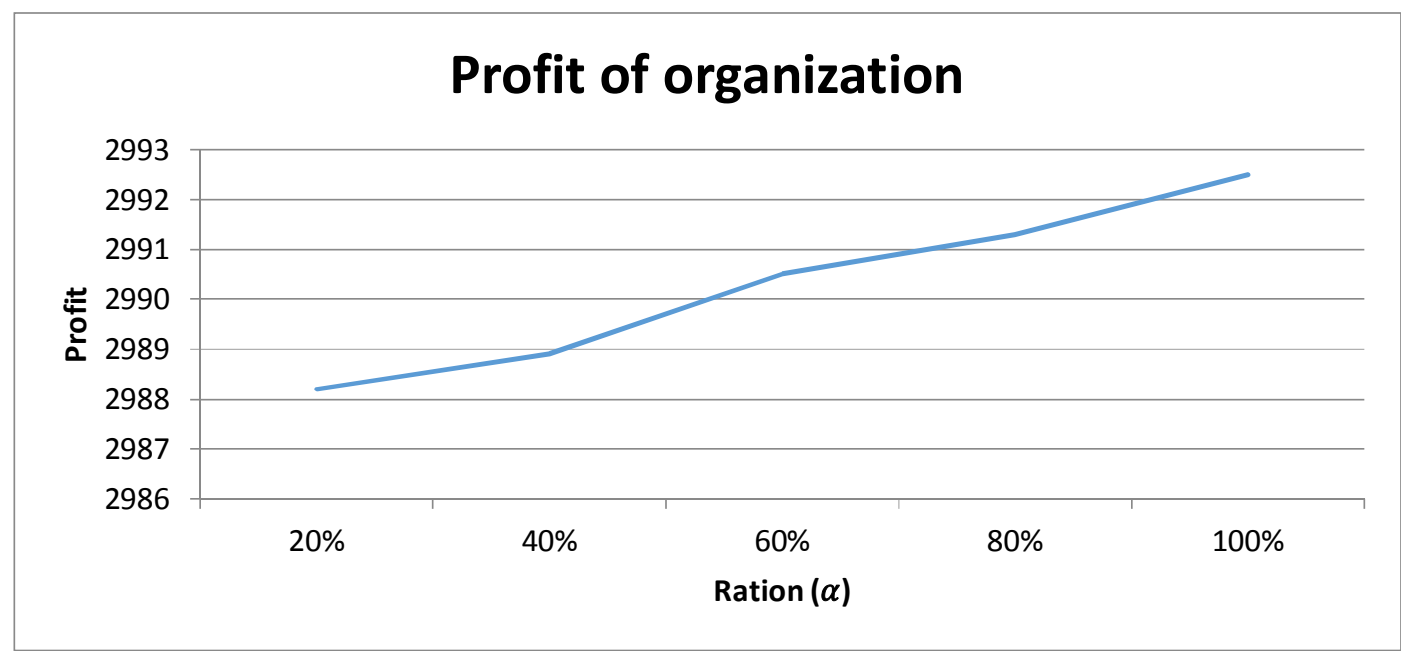

Fig. 5. The ratio $(\alpha)$

\section{Table 6}

Sensitivity analysis of the ratio $(\beta)$

\begin{tabular}{cccc}
\hline Percentage of inventory shortage $(\beta)$ & Profit & Inventory & \multicolumn{2}{c}{ Inventory } \\
& $H^{*}$ & $l_{1}^{*}$ & 194.66 \\
\hline $20 \%$ & 2983.6 & 256.17 & 194.82 \\
$40 \%$ & 2984.2 & 254.47 & 197.82 \\
$60 \%$ & 2985.9 & 249.42 & 192.63 \\
$80 \%$ & 2988.8 & 251.39 & 194.82 \\
$100 \%$ & 2992.5 & 243.00 & \\
\hline
\end{tabular}




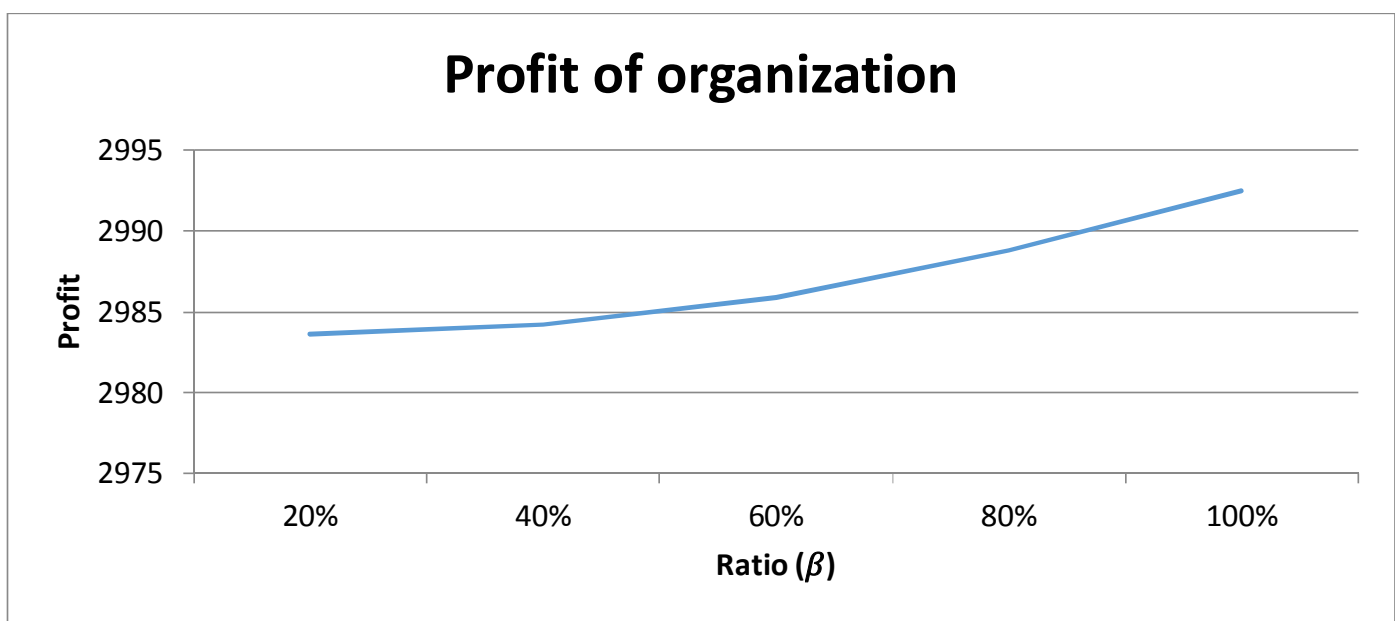

Fig. 6. Chart of the ratio $(\beta)$

Table 7

Sensitivity analysis of the ratio $(\delta)$

\begin{tabular}{cccc}
\hline Percentage of sell price $(\delta)$ & Profit & Inventory & Inventory \\
& $H^{*}$ & $l_{1}^{*}$ & $l_{2}^{*}$ \\
\hline $0 \%$ & 2992.5 & 243.00 & 194.82 \\
$20 \%$ & 2992.8 & 235.01 & 202.79 \\
$40 \%$ & 2993 & 243.02 & 194.72 \\
$60 \%$ & 2992 & 233.03 & 204.93 \\
$80 \%$ & 2992.9 & 240.23 & 197.76 \\
$100 \%$ & 2992.9 & 240.02 & 197.76 \\
\hline
\end{tabular}

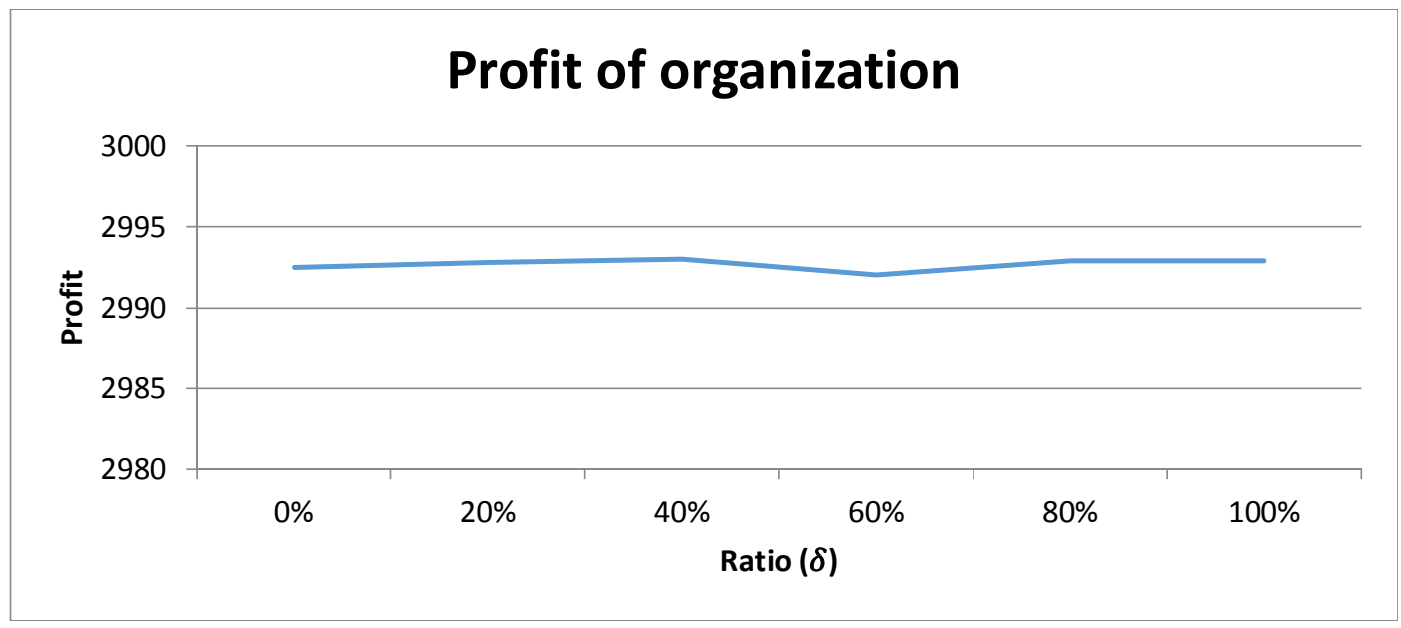

Fig. 7. Chart of the ratio $(\delta)$

Table 8 and Fig. 8 show that the proposed model maintained better profit $(H)$ than the method by Matsuyama (2006). As a result, a model that takes into account interdependent demand provides a better solution than a model based on independent demand. 
Table 8

Differences between the proposed model and Matsuyama (2006)

\begin{tabular}{|c|c|c|c|c|c|c|c|c|c|c|c|c|c|}
\hline $\begin{array}{l}\text { E } \\
\frac{0}{0} \\
0 \\
0 \\
0\end{array}$ & $p_{j}$ & $q_{j}$ & $s_{j}$ & $\pi$ & $\alpha$ & $\beta$ & $\delta$ & $\rho$ & $L$ & $N$ & $\begin{array}{c}\text { Expected } \\
\text { Profit of Pro- } \\
\text { posed Model } \\
\rho \neq 0 \\
\left(H^{*}\right)\end{array}$ & $\begin{array}{c}\text { Expected } \\
\text { Profit of Ma- } \\
\text { tsuyama } \\
(2006) \\
\rho=0 \\
\left(H^{*}\right)\end{array}$ & Gap \\
\hline $\mathrm{P} 1$ & 3 & 10 & 1 & 1 & $100 \%$ & $100 \%$ & $60 \%$ & $-50 \%$ & 144.33 & 286.67 & 2992.52 & 2856.67 & $4.76 \%$ \\
\hline P2 & 5 & 15 & 2 & 1 & $100 \%$ & $100 \%$ & $60 \%$ & $-40 \%$ & 200 & 400 & 3100.39 & 3000.39 & $3.33 \%$ \\
\hline P3 & 4 & 20 & 2 & 1 & $100 \%$ & $100 \%$ & $60 \%$ & $-60 \%$ & 250 & 500 & 4256.23 & 4058.20 & $4.88 \%$ \\
\hline P4 & 6 & 15 & 1.5 & 1 & $100 \%$ & $100 \%$ & $60 \%$ & $-50 \%$ & 100 & 200 & 1236.32 & 1006.22 & $22.87 \%$ \\
\hline P5 & 5 & 20 & 2 & 1 & $100 \%$ & $100 \%$ & $60 \%$ & $-70 \%$ & 220 & 440 & 3275.23 & 3025.45 & $8.26 \%$ \\
\hline \multirow[t]{3}{*}{ P6 } & 7 & 25 & 1.7 & 1 & $100 \%$ & $100 \%$ & $60 \%$ & $-80 \%$ & 300 & 600 & 5896.23 & 5536.35 & $6.50 \%$ \\
\hline & & & & & & & & & & & & Mean (Gap) & $8.43 \%$ \\
\hline & & & & & & & & & & & & $\begin{array}{c}\text { Variance } \\
\text { (Gap) }\end{array}$ & $0.53 \%$ \\
\hline
\end{tabular}

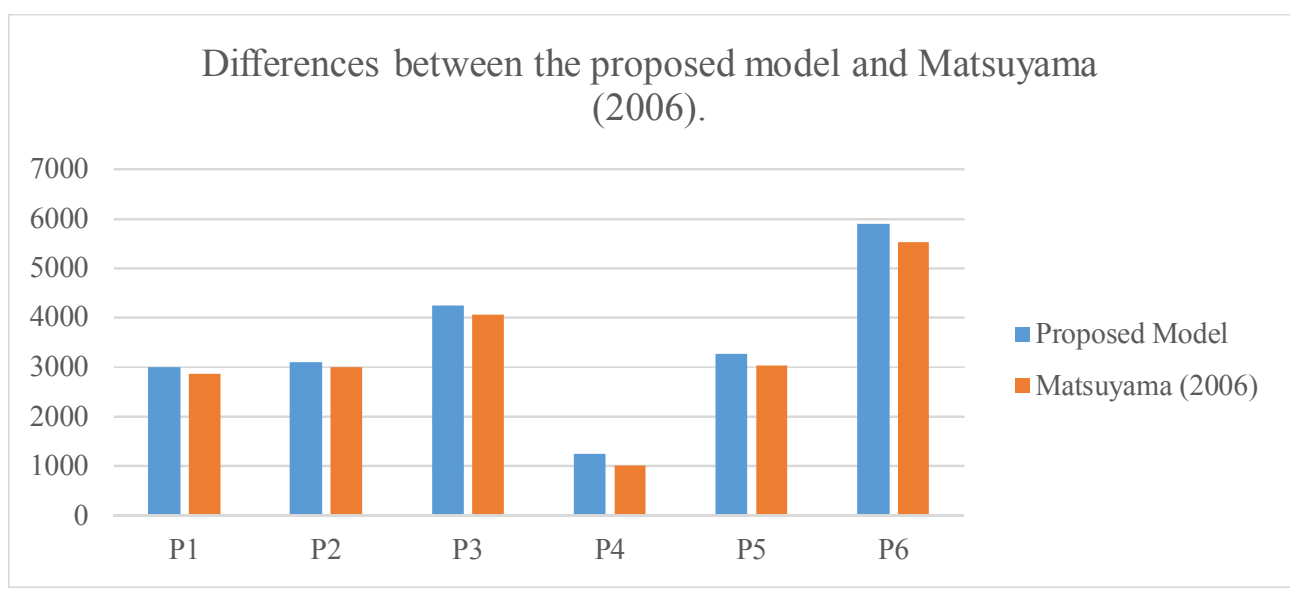

Fig. 8. Chart of Differences between the proposed model and Matsuyama (2006).

This model can be used in a number of applications, such as procurement of raw materials in projects (e.g., construction, bridge-building and molding) where demand of different periods is interdependent.

\section{Conclusion}

Considering the NP-hard complexity of start time and ordering problems for two-period projects, a meta-heuristic genetic algorithm was used to solve this stochastic mathematical model. The innovation of the present study is the use of a bivariate normal distribution for formulization of interdependence of demand of different periods. This increases the complexity of inventory control models like the twoperiod newsvendor problem and has received little attention in the literature. Ultimately, the genetic algorithm was used to determine the optimal start times and inventory levels of periods based on the levels of demand, with the objective of maximizing the mean profit of project-oriented organizations. As a result, a model that takes into account the interdependent demand provides a better solution than a model based on independent demand.

Possible directions for future research include the development of start time scheduling and ordering problems with interdependent demand for $n$-period projects, fuzzy demand and objective functions, perishable materials, multiple products, multiple organizations, competitive environments, risk-involved projects, suppliers with discount policies, and wait times of more than zero. Future studies could 
also consider resource constraints of suppliers and organizations, and use of other metaheuristic algorithms for solutions.

\section{Appendix 1:}

\section{Proposition 1 :}

We want to prove $F\left(l_{1}^{*}\right)=\int_{-\infty-\infty}^{\infty} \int_{1}^{l_{1}^{*}} f\left(x_{1}, x_{2}\right) d x_{1} d x_{2}=\frac{q_{1}-p_{1}+\pi-\beta\left(\delta q_{1}+(1-\delta) q_{2}\right)+p_{2} \beta}{q_{1}+\pi-\beta\left(\delta q_{1}+(1-\delta) q_{2}\right)+p_{2} \beta+\alpha\left(s_{1}-p_{2}\right)}$ and $F\left(l_{2}^{*}\right)=\int_{-\infty}^{\infty} \int_{-\infty}^{l_{2}^{*}} f\left(x_{1}, x_{2}\right) d x_{2} d x_{1}=\frac{q_{2}-p_{2}+\pi}{q_{2}+\pi}$.

\section{Proof:}

Eq. (8) is differentiated to determine the optimal point:

$$
\frac{\partial}{\partial l_{1}} H\left(l_{1}, l_{2}, x_{1}, x_{2}\right)=0
$$

Let $H_{j}\left(l_{1}, l_{2}, x_{1}, x_{2}\right)=h_{2 j}\left(l_{1}, l_{2}, x_{1}, x_{2}\right) f\left(x_{1}, x_{2}\right)$,

$H\left(l_{1}, l_{2}, x_{1}, x_{2}\right)=\sum_{j=1}^{4} \int_{p\left(l_{2}\right)} \int_{q\left(l_{1}\right)} H_{j}\left(l_{1}, l_{2}, x_{1}, x_{2}\right) d x_{1} d x_{2}$

$\frac{\partial}{\partial l_{1}} H_{j}\left(l_{1}, l_{2}, x_{1}, x_{2}\right)=\frac{\partial}{\partial l_{1}} h_{2 j}\left(l_{1}, l_{2}, x_{1}, x_{2}\right) f\left(x_{1}, x_{2}\right)=f\left(x_{1}, x_{2}\right) \frac{\partial}{\partial l_{1}} h_{2 j}\left(l_{1}, l_{2}, x_{1}, x_{2}\right)$.

It can be shown that the derivative of $h_{2 j}$ with respect to $l_{1}$ is linear:

Let $k_{j}=\frac{\partial}{\partial l_{1}} h_{2 j}\left(l_{1}, l_{2}, x_{1}, x_{2}\right)$,

$\frac{\partial}{\partial l_{1}} H_{j}\left(l_{1}, l_{2}, x_{1}, x_{2}\right)=k_{j} f\left(x_{1}, x_{2}\right)$,

$\frac{\partial}{\partial l_{1}} H\left(l_{1}, l_{2}, x_{1}, x_{2}\right)=\frac{\partial}{\partial l_{1}} \sum_{j=1}^{4} \int_{p\left(l_{2}\right)} \int_{q\left(l_{1}\right)} H_{j}\left(l_{1}, l_{2}, x_{1}, x_{2}\right) d x_{1} d x_{2}$

$=\sum_{j=1}^{4} \int_{p\left(l_{2}\right)} \frac{\partial}{\partial l_{1}} \int_{q\left(l_{1}\right)} H_{j}\left(l_{1}, l_{2}, x_{1}, x_{2}\right) d x_{1} d x_{2}$

$=\sum_{j=1}^{4} \int_{p\left(l_{2}\right)}\left[\int_{q_{1}\left(l_{1}\right)}^{q_{2}\left(l_{1}\right)} \frac{\partial}{\partial l_{1}} H_{j}\left(l_{1}, l_{2}, x_{1}, x_{2}\right) d x_{1}+\frac{\partial}{\partial l_{1}} q_{2}\left(l_{1}\right) H_{j}\left(l_{1}, l_{2}, q_{2}\left(l_{1}\right), x_{2}\right)-\frac{\partial}{\partial l_{1}} q_{1}\left(l_{1}\right) H_{j}\left(l_{1}, l_{2}, q_{2}\left(l_{1}\right), x_{2}\right)\right] d x_{2}$

$=\sum_{j=1}^{4} \int_{p\left(l_{2}\right)}\left[\int_{q_{1}\left(l_{1}\right)}^{q_{2}\left(l_{1}\right)} k_{j} f\left(x_{1}, x_{2}\right) d x_{1}+\frac{\partial}{\partial l_{1}} q_{2}\left(l_{1}\right) H_{j}\left(l_{1}, l_{2}, q_{2}\left(l_{1}\right), x_{2}\right)-\frac{\partial}{\partial l_{1}} q_{1}\left(l_{1}\right) H_{j}\left(l_{1}, l_{2}, q_{2}\left(l_{1}\right), x_{2}\right)\right] d x_{2}$

$=\int_{-\infty}^{l_{2}} \int_{-\infty}^{l_{1}} k_{1} f\left(x_{1}, x_{2}\right) d x_{1} d x_{2}+\int_{l_{2}}^{\infty} \int_{-\infty}^{l_{1}} k_{2} f\left(x_{1}, x_{2}\right) d x_{1} d x_{2}$

$+\int_{-\infty}^{l_{2}} \int_{l_{1}}^{\infty} k_{3} f\left(x_{1}, x_{2}\right) d x_{1} d x_{2}+\int_{l_{2}}^{\infty} \int_{1}^{\infty} k_{4} f\left(x_{1}, x_{2}\right) d x_{1} d x_{2}$ 
$+\int_{-\infty}^{l_{2}}\left[H_{1}\left(l_{1}, l_{2}, l_{1}, x_{2}\right)-H_{3}\left(l_{1}, l_{2}, l_{1}, x_{2}\right)\right] d x_{2}+\int_{l_{2}}^{\infty}\left[H_{2}\left(l_{1}, l_{2}, l_{1}, x_{2}\right)-H_{4}\left(l_{1}, l_{2}, l_{1}, x_{2}\right)\right] d x_{2}$.

It can be shown that the following relations hold:

$H_{1}\left(l_{1}, l_{2}, l_{1}, x_{2}\right)-H_{3}\left(l_{1}, l_{2}, l_{1}, x_{2}\right)=0$,

$H_{2}\left(l_{1}, l_{2}, l_{1}, x_{2}\right)-H_{4}\left(l_{1}, l_{2}, l_{1}, x_{2}\right)=0$.

Eq. s (A-2) and (A-3) are established as follows:

$H_{1}\left(l_{1}, l_{2}, q_{2}\left(l_{1}\right), x_{2}\right)=h_{21}\left(l_{1}, l_{2}, l_{1}, x_{2}\right) f\left(l_{1}, x_{2}\right)$,

$H_{2}\left(l_{1}, l_{2}, q_{2}\left(l_{1}\right), x_{2}\right)=h_{22}\left(l_{1}, l_{2}, l_{1}, x_{2}\right) f\left(l_{1}, x_{2}\right)$,

$H_{3}\left(l_{1}, l_{2}, q_{2}\left(l_{1}\right), x_{2}\right)=h_{23}\left(l_{1}, l_{2}, l_{1}, x_{2}\right) f\left(l_{1}, x_{2}\right)$,

$H_{4}\left(l_{1}, l_{2}, q_{2}\left(l_{1}\right), x_{2}\right)=h_{24}\left(l_{1}, l_{2}, l_{1}, x_{2}\right) \cdot f\left(l_{1}, x_{2}\right)$,

$H_{1}\left(l_{1}, l_{2}, l_{1}, x_{2}\right)-H_{3}\left(l_{1}, l_{2}, l_{1}, x_{2}\right)=\left(h_{21}\left(l_{1}, l_{2}, l_{1}, x_{2}\right)-h_{23}\left(l_{1}, l_{2}, l_{1}, x_{2}\right)\right) f\left(l_{1}, x_{2}\right)$.

$H_{2}\left(l_{1}, l_{2}, l_{1}, x_{2}\right)-H_{4}\left(l_{1}, l_{2}, l_{1}, x_{2}\right)=\left(h_{22}\left(l_{1}, l_{2}, l_{1}, x_{2}\right)-h_{24}\left(l_{1}, l_{2}, l_{1}, x_{2}\right)\right) f\left(l_{1}, x_{2}\right)$.

Because in Eq. (4) and Eq. (6) gives $h_{21}\left(l_{1}, l_{2}, l_{1}, x_{2}\right)-h_{23}\left(l_{1}, l_{2}, l_{1}, x_{2}\right)=0$ then

$H_{1}\left(l_{1}, l_{2}, l_{1}, x_{2}\right)-H_{3}\left(l_{1}, l_{2}, l_{1}, x_{2}\right)=0$, and also in Eq. (5) and Eq. (7) gives

$h_{22}\left(l_{1}, l_{2}, l_{1}, x_{2}\right)-h_{24}\left(l_{1}, l_{2}, l_{1}, x_{2}\right)=0$, then $H_{2}\left(l_{1}, l_{2}, l_{1}, x_{2}\right)-H_{4}\left(l_{1}, l_{2}, l_{1}, x_{2}\right)=0$.

After substituting the above equation into Eq. (A-1) gives:

$$
\begin{aligned}
& \frac{\partial}{\partial l_{1}} H\left(l_{1}, l_{2}, x_{1}, x_{2}\right)=\int_{-\infty}^{l_{2}} \int_{-\infty}^{l_{1}} k_{1} f\left(x_{1}, x_{2}\right) d x_{1} d x_{2}+\int_{l_{2}-\infty}^{\infty} \int_{-\infty}^{l_{1}} k_{2} f\left(x_{1}, x_{2}\right) d x_{1} d x_{2} \\
& +\int_{-\infty}^{l_{2}} \int_{l_{1}}^{\infty} k_{3} f\left(x_{1}, x_{2}\right) d x_{1} d x_{2}+\iint_{l_{2}}^{\infty} \int_{l_{1}}^{\infty} k_{4} f\left(x_{1}, x_{2}\right) d x_{1} d x_{2} \\
& =k_{1} \int_{-\infty}^{l_{2}} \int_{-\infty}^{l_{1}} f\left(x_{1}, x_{2}\right) d x_{1} d x_{2}+k_{2} \int_{l_{2}-\infty}^{\infty} \int_{l_{1}}^{l_{1}} f\left(x_{1}, x_{2}\right) d x_{1} d x_{2}+k_{3} \int_{-\infty}^{l_{2}} \int_{l_{1}}^{\infty} f\left(x_{1}, x_{2}\right) d x_{1} d x_{2}+k_{4} \iint_{l_{2}}^{\infty} \int_{1}^{\infty} f\left(x_{1}, x_{2}\right) d x_{1} d x_{2} \\
& =k_{1} F\left(l_{1}, l_{2}\right)+k_{2},
\end{aligned}
$$

We know from Eqs. (4-7):

$k_{1}=\frac{\partial}{\partial l_{1}} h_{21}\left(l_{1}, l_{2}, x_{1}, x_{2}\right)=-p_{1}-s_{1} \alpha+\alpha p_{2}$,

$k_{2}=\frac{\partial}{\partial l_{1}} h_{22}\left(l_{1}, l_{2}, x_{1}, x_{2}\right)=-p_{1}-s_{1} \alpha+\alpha p_{2}$,

$k_{3}=\frac{\partial}{\partial l_{1}} h_{23}\left(l_{1}, l_{2}, x_{1}, x_{2}\right)=q_{1}-p_{1}+\pi-\beta\left(\delta q_{1}+(1-\delta) q_{2}\right)+p_{2} \beta$,

$k_{1}=k_{2} \quad, \quad k_{3}=k_{4}$,

By substituting the above equation into Eq. (A-4), we have:

$\frac{\partial}{\partial l_{1}} H\left(l_{1}, l_{2}, x_{1}, x_{2}\right)=\left(k_{1}-k_{2}-k_{3}+k_{4}\right) F\left(l_{1}, l_{2}\right)+\left(k_{2}-k_{4}\right) F\left(l_{1}\right)+\left(k_{3}-k_{4}\right) F\left(l_{2}\right)+k_{4}$

$=\left(k_{2}-k_{4}\right) F\left(l_{1}\right)+k_{4}=0$.

Finally $F\left(l_{1}\right)=\frac{k_{4}}{k_{4}-k_{2}}$ and proposition is proved. 
Similarly subjecting Eq. (9) to the process explained in above,

$F\left(l_{2}^{*}\right)=\int_{-\infty}^{\infty} \int_{-\infty}^{l_{2}^{*}} f\left(x_{1}, x_{2}\right) d x_{2} d x_{1}=\frac{q_{2}-p_{2}+\pi}{q_{2}+\pi}$ is proved.

\section{Appendix 2:}

The aim is to complete the elements of a Hessian matrix (second derivative test). For this purpose, first and second derivatives of the mean profit function with respect to $l_{1}, l_{2}$ are obtained (Eq. (A-5)):

$$
\begin{aligned}
& \frac{\partial}{\partial l_{1}} H\left(l_{1}, l_{2}, x_{1}, x_{2}\right)=\left(k_{2}-k_{4}\right) F\left(l_{1}\right)+k_{4}, \\
& \frac{\partial}{\partial l_{1}^{2}} H\left(l_{1}, l_{2}, x_{1}, x_{2}\right)=\left(k_{2}-k_{4}\right) \frac{\partial}{\partial l_{1}} F\left(l_{1}\right) \\
& =-\left(q_{1}+\pi-\beta\left(\delta q_{1}+(1-\delta) q_{2}\right)+p_{2} \beta+\alpha\left(s_{1}-p_{2}\right)\right) \frac{\partial}{\partial l_{1}} F\left(l_{1}\right), \\
& \frac{\partial}{\partial l_{1}} F\left(l_{1}\right)=\frac{\partial}{\partial l_{1}} \int_{-\infty}^{\infty} \int_{-\infty}^{l_{1}} f\left(x_{1}, x_{2}\right) d x_{1} d x_{2}=\int_{-\infty}^{\infty} \frac{\partial}{\partial l_{1}} \int_{-\infty}^{l_{1}} f\left(x_{1}, x_{2}\right) d x_{1} d x_{2} \\
& =\int_{-\infty}^{\infty}\left[\int_{-\infty}^{l_{1}} \frac{\partial}{\partial l_{1}} f\left(x_{1}, x_{2}\right) d x_{1}+f\left(l_{1}, x_{2}\right)\right] d x_{2}=\int_{-\infty}^{\infty} f\left(l_{1}, x_{2}\right) d x_{2}>0 .
\end{aligned}
$$

When $\left(k_{2}-k_{4}\right)<0$, the second order derivative will be $\frac{\partial}{\partial l_{1}{ }^{2}} H\left(l_{1}^{*}, l_{2}^{*}, x_{1}, x_{2}\right)<0$ (Eq. (A-6)):

$\frac{\partial}{\partial l_{1}^{2}} H\left(l_{1}^{*}, l_{2}^{*}, x_{1}, x_{2}\right)=\left(k_{2}-k_{4}\right) \frac{\partial}{\partial l_{1}} F\left(l_{1}\right)_{l_{2}=l_{2}^{*}}^{l_{1}=l_{1}^{*}}<0$,

$\frac{\partial}{\partial l_{2} \partial l_{1}} H\left(l_{1}, l_{2}, x_{1}, x_{2}\right)=0$

$\frac{\partial}{\partial l_{2}} H\left(l_{1}, l_{2}, x_{1}, x_{2}\right)=\left(k_{3}^{\prime}-k_{4}^{\prime}\right) F\left(l_{2}\right)+k_{4}^{\prime}$,

$\frac{\partial}{\partial l_{2}^{2}} H\left(l_{1}, l_{2}, x_{1}, x_{2}\right)=\left(k_{3}^{\prime}-k_{4}^{\prime}\right) \frac{\partial}{\partial l_{2}} F\left(l_{2}\right)=-\left(q_{2}+\pi\right) \frac{\partial}{\partial l_{2}} F\left(l_{2}\right)$,

$\frac{\partial}{\partial l_{2}} F\left(l_{2}\right)=\frac{\partial}{\partial l_{2}} \int_{-\infty}^{\infty} \int_{-\infty}^{l_{2}} f\left(x_{1}, x_{2}\right) d x_{2} d x_{1}$

$=\int_{-\infty}^{\infty} \frac{\partial}{\partial l_{2}} \int_{-\infty}^{l_{1}} f\left(x_{1}, x_{2}\right) d x_{2} d x_{1}=\int_{-\infty}^{\infty}\left[\int_{-\infty}^{l_{2}} \frac{\partial}{\partial l_{2}} f\left(x_{1}, x_{2}\right) d x_{2}+f\left(x_{1}, l_{2}\right)\right] d x_{1}=\int_{-\infty}^{\infty} f\left(x_{1}, l_{2}\right) d x_{1}>0$,

$\frac{\partial}{\partial l_{2}^{2}} H\left(l_{1}^{*}, l_{2}^{*}, x_{1}, x_{2}\right)=\left(k_{3}^{\prime}-k_{4}^{\prime}\right) \frac{\partial}{\partial l_{2}} F\left(l_{2}\right)_{l_{2}=l_{2}^{*}}^{l_{1}=l_{1}^{*}}<0$,

$\frac{\partial}{\partial l_{1} \partial l_{2}} H\left(l_{1}, l_{2}, x_{1}, x_{2}\right)=0$

$H m\left(l_{1}=l_{1}^{*}, l_{2}=l_{2}^{*}\right)=\left(\begin{array}{cc}\frac{\partial}{\partial l_{1}^{2}} H & \frac{\partial}{\partial l_{1} \partial l_{2}} H \\ \frac{\partial}{\partial l_{2} \partial l_{1}} H & \frac{\partial}{\partial l_{2}^{2}} H\end{array}\right)=\left(\begin{array}{cc}\left(k_{2}-k_{4}\right) \frac{\partial}{\partial l_{1}} F\left(l_{1} l_{l_{2}=l_{2}^{\prime}}^{l_{1}=l_{1}^{\prime}}\right. & 0 \\ 0 & \left(k_{3}^{\prime}-k_{4}^{\prime}\right) \frac{\partial}{\partial l_{2}} F\left(l_{2}\right)_{l_{2}=l_{2}^{*}}^{l_{1} l_{l}^{*}}\end{array}\right)$. 
By definition, the second derivative test is expressed as (Eq. (A-7)):

$$
M(x, y)=\operatorname{det}(H(x, y))=f_{x x}(x, y) f_{y y}(x, y)-\left(f_{x y}(x, y)\right)^{2} \text {. }
$$

If $M(a, b)>0$ and $f_{x x}(a, b)<0$, then $(a, b)$ is the relative maximum of $f$, therefore (Eq. (A-8)) is:

$$
\begin{aligned}
& M(x, y)=\left|H m\left(l_{1}=l_{1}^{*}, l_{2}=l_{2}^{*}\right)\right|>0 \\
& \left(k_{2}-k_{4}\right) \frac{\partial}{\partial l_{1}} F\left(l_{1}\right)_{l_{2}=l_{2}^{*}}^{l_{1}=l_{1}^{*}}<0 .
\end{aligned}
$$

The determinant of $H$ for $l_{1}^{*}, l_{2}^{*}$ is positive, and $f_{x x}(a, b)<0$; therefore $l_{1}^{*}, l_{2}^{*}$ are the relative maximum for $H\left(l_{1}^{*}, l_{2}^{*}, x_{1}, x_{2}\right)$.

\section{Acknowledgement}

The authors would like to thank the anonymous referees for constructive comments on earlier version of this paper.

\section{References}

Abramowitz, M., \& Stegun, I. A. (1964). Handbook of mathematical functions: with formulas, graphs, and mathematical tables (Vol. 55). Courier Corporation.

Alwan, L. C., Xu, M., Yao, D. Q., \& Yue, X. (2016). The dynamic newsvendor model with correlated demand. Decision Sciences, 47(1), 11-30.

Behret, H., \& Kahraman, C. (2010). A multi-period newsvendor problem with pre-season extension under fuzzy demand. Journal of Business Economics and Management, 11(4), 613-629.

Burnetas, A., Gilbert, S. M., \& Smith, C. E. (2007). Quantity discounts in single-period supply contracts with asymmetric demand information. IIE Transactions, 39(5), 465-479.

Chen, S. P., \& Ho, Y. H. (2011). Analysis of the newsboy problem with fuzzy demands and incremental discounts. International Journal of Production Economics, 129(1), 169-177.

Chen, S. P., \& Ho, Y. H. (2013). Optimal inventory policy for the fuzzy newsboy problem with quantity discounts. Information Sciences, 228, 75-89.

Diabat, A. (2014). Hybrid algorithm for a vendor managed inventory system in a two-echelon supply chain. European Journal of Operational Research, 238(1), 114-121.

Ding, S., \& Gao, Y. (2014). The $(\sigma, S)$ policy for uncertain multi-product newsboy problem. Expert Systems with Applications, 41(8), 3769-3776.

Dye, C. Y., \& Ouyang, L. Y. (2005). An EOQ model for perishable items under stock-dependent selling rate and time-dependent partial backlogging. European Journal of Operational Research, 163(3), 776-783.

Geiger, M. J. (2017). A multi-threaded local search algorithm and computer implementation for the multi-mode, resource-constrained multi-project scheduling problem. European Journal of Operational Research, 256(3), 729-741.

Geisler, M. A. (1963). A study of inventory theory. Management Science, 9(3), 490-497.

Ghaddar, B., Sakr, N., \& Asiedu, Y. (2016). Spare parts stocking analysis using genetic programming. European Journal of Operational Research, 252(1), 136-144.

Hanasusanto, G. A., Kuhn, D., Wallace, S. W., \& Zymler, S. (2015). Distributionally robust multi-item newsvendor problems with multimodal demand distributions. Mathematical Programming, 152(12), 1-32.

Holland, J. H. (1975). Adaptation in natural and artificial systems: an introductory analysis with applications to biology, control, and artificial intelligence. U Michigan Press. 
Huang, D., Zhou, H., \& Zhao, Q. H. (2011). A competitive multiple-product newsboy problem with partial product substitution. Omega, 39(3), 302-312.

Jun, S., \& Park, J. (2015). A hybrid genetic algorithm for the hybrid flow shop scheduling problem with nighttime work and simultaneous work constraints: A case study from the transformer industry. Expert Systems with Applications, 42(15), 6196-6204.

Kamburowski, J. (2014). The distribution-free newsboy problem under the worst-case and best-case scenarios. European Journal of Operational Research, 237(1), 106-112.

Kamburowski, J. (2015). The distribution-free newsboy problem and the demand skew. International Transactions in Operational Research, 22(5), 929-946.

Lotfi, R., Amin Nayeri, M. (2016). Multi-objective capacitated facility location with hybrid fuzzy Simplex and genetic algorithm approach. Journal of Industrial Engineering Research in Production Systems, 4(7), 81-91.

Lotfi, R., Mehrjerdi, Y. Z., \& Mardani, N. (2017). A multi-objective and multi-product advertising billboard location model with attraction factor mathematical modeling and solutions. International Journal of Applied Logistics, 7(1), 64-86.

Marinakis, Y., Marinaki, M., Doumpos, M., Matsatsinis, N., \& Zopounidis, C. (2008). A hybrid stochastic genetic-GRASP algorithm for clustering analysis. Operational Research, 8(1), 33-46.

Matsuyama, K. (2006). The multi-period newsboy problem. European Journal of Operational Research, 171(1), 170-188.

Mousavi, S. M., Hajipour, V., Niaki, S. T. A., \& Aalikar, N. (2014). A multi-product multi-period inventory control problem under inflation and discount: a parameter-tuned particle swarm optimization algorithm. The International Journal of Advanced Manufacturing Technology, 70(9-12), 1739-1756.

Okyay, H. K., Karaesmen, F., \& Özekici, S. (2014). Newsvendor models with dependent random supply and demand. Optimization Letters, 8(3), 983-999.

Pal, B., Sana, S. S., \& Chaudhuri, K. (2015). A distribution-free newsvendor problem with nonlinear holding cost. International Journal of Systems Science, 46(7), 1269-1277.

Perakis, G., \& Sood, A. (2004). Competitive multi-period pricing with fixed inventories. High Performance Computation for Engineered Systems (HPCES)

Puga, M. S., \& Tancrez, J. S. (2017). A heuristic algorithm for solving large location-inventory problems with demand uncertainty. European Journal of Operational Research, 259(2), 413-423.

Qiongbing, Z., \& Lixin, D. (2016). A new crossover mechanism for genetic algorithms with variablelength chromosomes for path optimization problems. Expert Systems with Applications, 60, 183189.

Roy, S. K., \& Mula, P. (2016). Solving matrix game with rough payoffs using genetic algorithm. $O p-$ erational Research, 16(1), 117-130.

Sana, S. S. (2012). Price sensitive demand with random sales price-a newsboy problem. International Journal of Systems Science, 43(3), 491-498.

Singh, S., Kumar, K., Bhattacharya, A., \& Rai, H. (2016). Estimating and testing the significance of correlation coefficient obtained from truncated bivariate normal distribution. Journal of Interdisciplinary Mathematics, 19(2), 245-251.

Sivanandam, S. N., \& Deepa, S. N. (2007). Introduction to genetic algorithms. Springer Science \& Business Media.

Tran, K. P., Castagliola, P., \& Celano, G. (2016). Monitoring the ratio of population means of a bivariate normal distribution using CUSUM type control charts. Statistical Papers, 1-27.

Wang, C. X., \& Webster, S. (2009). The loss-averse newsvendor problem. Omega, 37(1), 93-105.

Willoughby, K. A. (1998). Modelling assistance for project procurement and disposal decisions. University of Calgary.

Yuan, J. J., Cheng, T. E., \& Ng, C. T. (2007). NP-hardness of the single-variable-resource scheduling problem to minimize the total weighted completion time. European Journal of Operational Research, 178(2), 631-633.

Zhang, B., \& Du, S. (2010). Multi-product newsboy problem with limited capacity and outsourcing. 
European Journal of Operational Research, 202(1), 107-113.

Zhang, B., \& Hua, Z. (2010). A portfolio approach to multi-product newsboy problem with budget constraint. Computers \& Industrial Engineering, 58(4), 759-765.

Zhang, G. (2010). The multi-product newsboy problem with supplier quantity discounts and a budget constraint. European Journal of Operational Research, 206(2), 350-360.

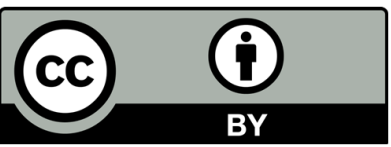

(C) 2017 by the authors; licensee Growing Science, Canada. This is an open access article distributed under the terms and conditions of the Creative Commons Attribution (CC-BY) license (http://creativecommons.org/licenses/by/4.0/). 